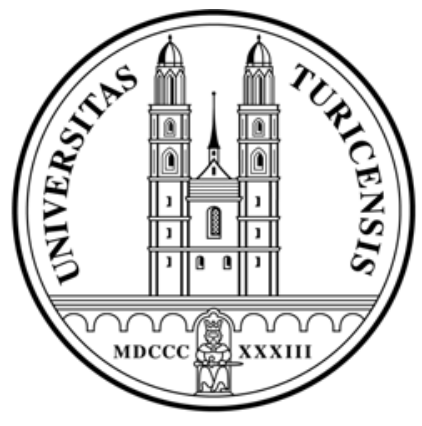

Institute for Empirical Research in Economics

University of Zurich

Working Paper Series

ISSN 1424-0459

Working Paper No. 087

Direct versus Intermediated Finance:

an Old Question and a New Answer

Anke Gerber

March 2006 


\title{
Direct versus Intermediated Finance: an Old Question and a New Answer*
}

\author{
Anke Gerber ${ }^{\dagger}$
}

March 2006

\begin{abstract}
We consider a closed economy where a risk neutral bank competes with a competitive bond market. Firms can finance a risky project either by a bank credit or by issuing a bond which is directly sold to risk averse investors who also hold safe deposits at the bank. We show that the bank tends to allocate more capital to lower quality projects but there are some interesting qualifications. If the asymmetric information concerns only the success probability, then we observe adverse selection while if it concerns only the expected return, bad types are driven out of the market.

Keywords: Credit market, bond market, risk aversion, adverse selection. JEL classification: D82, G21.
\end{abstract}

*I am grateful to Thorsten Hens, Jörg Naeve, Georg Nöldeke, Bodo Vogt and, in particular, to two referees for valuable comments. I also thank seminar participants at Bonn, Hohenheim, Zurich, and to participants at the EEA meeting in Lausanne and the annual meeting of the association "Verein für Socialpolitik" in Innsbruck.

$\dagger$ Institute for Empirical Research in Economics, Plattenstr. 32, CH-8032 Zurich, Switzerland. E-mail: agerber@iew.unizh.ch. 


\section{Introduction}

Corporations have to rely on external financing whenever internal cash flows are too small to finance new projects. The largest fraction of external financing by U.S. nonfinancial corporations comes from debt, while net equity issues are mostly negative. ${ }^{1}$ The starting point of our paper is a striking observation concerning the corporate debt structure in the presence of private (bank) and public debt markets (bonds). There is significant empirical evidence of the fact that bad risks are predominantly financed by banks while good risks obtain most of their funds from public debt markets. An early study by James (1987) shows that firms announcing new bank loans and privately placed debt have a higher default risk and are on average smaller than those announcing publicly placed straight debt offerings. In an analysis of corporate financing in Japan, Hoshi et al. (1993) find that high net worth firms are more likely to use public than bank debt. Johnson (1997) presents evidence of the fact that the proportion of bank debt is negatively related to firm size and age and positively related to leverage and to earnings growth volatility. All these characteristics can serve as proxies for credit risk: Small and young firms as well as highly leveraged firms or firms with high earnings growth volatility can generally be considered more risky than firms with the opposite characteristics. Similar results for more general private debt are reported in Krishnaswami, Spindt, and Subramaniam (1999). Finally, the tremendous growth of the market for credit derivatives in the last decade can also be viewed as evidence for the risk accumulation by banks. ${ }^{2}$

The theoretical literature that provides explanations for the observed debt structure of firms is large and too extensive to be reviewed in detail. Hence, we only give a brief overview over the proposed explanations and contrast them with the contribution of this paper. The literature mainly focusses on three aspects that can explain the choice between bank loans and public debt, namely information costs, monitoring and renegotiation. The information cost aspect was

\footnotetext{
${ }^{1}$ See the Flow of Funds Account of the Federal Reserve System, March 9, 2006, Table F.102.

${ }^{2}$ Banks and other financial institutions are the main participants in the credit derivatives market, which according to the Credit Derivatives Report 2003/2004 of the British Bankers' Association grew from $\$ 180$ billion in 1997 to about $\$ 5,000$ billion in 2004 and is expected to exceed $\$ 8,000$ billion in 2006 .
} 
stressed by Fama (1985) who pointed out that the issue of public debt requires the provision of information for a large group of potential debt holders (via bond ratings or audits) while there is only one contracting party in case of a bank loan. Fama (1985) concluded that the information cost for public debt financing is higher for smaller than for larger firms, so that small firms prefer bank loans while large firms prefer public debt. This prediction is consistent with the empirical evidence in James (1987) and Johnson (1997). In the sequel several authors have pointed out that a bank loan involves close monitoring of the financed project which is not the case for publicly traded debt. Several papers take this monitoring activity to be the defining characteristic of a bank. Since monitoring is costly bank loans are more expensive than public debt and hence only those firms rely on bank credit which require monitoring. These can be firms that have not built up a reputation of repaying their debt as in Diamond (1991) or firms that are highly leveraged so that the market does not expect them to behave diligently if they are not monitored as in Holmstrom and Tirole (1997). These predictions are consistent with the empirical observation that firms announcing new bank loans have a higher default risk (James, 1987) and have a higher leverage (Johnson, 1997) than firms announcing the issue of public debt. Finally, it is much easier to renegotiate a bank loan than publicly traded debt since the holders of public debt are typically widely dispersed while a bank loan only involves one contracting partner. Debt renegotiation can prevent inefficient liquidation and hence firms with a high probability of financial distress prefer bank loans over bonds (see Chemmanur and Fulghieri, 1994, and Bolton and Freixas, 2000). This prediction is consistent with the observation that bank debt is increasing in the earnings growth volatility (see Johnson, 1997). Also, as Rajan (1992) argues, debt renegotiation is costly since banks gain bargaining power over the firm's profits once projects have begun. He concludes that firms with high quality (=high success probability) projects will prefer public debt while those with low quality projects prefer bank loans, which is consistent with the empirical evidence in James (1987).

The contribution of our paper is to offer an alternative and to some extent much simpler answer to the old question, why banks tend to allocate more capital to riskier or more general lower quality projects. Our emphasis is on the 
role of banks in diversifying risks. While the previous literature has focussed on a risk neutral world, where there is an infinitely elastic supply of funds at an exogenously given interest rate, we take the view that risk aversion is a predominant phenomenon, which has to be taken into account in any full model of bank and capital market lending. We will show that the investors' risk aversion alone together with the bank's ability to diversify risk can explain the debt allocation between banks and bond markets.

In order to derive the implications of a bank's risk diversification activity we disregard the monitoring role of banks and choose a setting with asymmetric information prior to contracting (firms have a given project type prior to contracting). In our model a monopolistic bank faces competition from a bond market which limits the rent extraction of the bank. Hence we combine a principal-agent situation with a competitive market. ${ }^{3}$ Risk neutral firms seek finance for projects and can obtain credit from the bank or issue bonds. There are two types of firms which differ in the quality of their project. Only the proportions of the two types of firms are common knowledge while the type of a single firm is its private information. Following Hellmann and Stiglitz (2000) we measure project quality along two dimensions, namely the expected return and the success probability of a project. Risk averse investors can invest their capital in safe bank deposits or in risky bonds. Investment in bonds is risky because by assumption investors cannot diversify their risk at the bond market. This assumption can be justified by the fact that building a well diversified fund of bonds is too costly for individual investors. By contrast the bank can diversify its risk by giving loans to a pool of firms. The bank sets the credit volume and the interest rates on deposits and credit such as to maximize expected profits. In doing so it anticipates the equilibrium on the bond market. The firms in our model have no financial resources and there is no equity market. Hence, collateral cannot serve as a screening device and the bank can only screen the firms by setting the interest rate so high that one firm type does not invest at all. In this case we say that the economy is in

\footnotetext{
${ }^{3}$ There is some empirical evidence of monopoly power at the level of individual banks (see Cosimano and McDonald, 1998). However, it turns out that the results in our paper are not driven by the monopoly power of the bank. Similar qualitative results can be obtained for an oligopolistic banking sector (see section 3.1).
} 
a "screening equilibrium," while a "pooling equilibrium" refers to the case where both types of firms invest.

Different from most models on direct versus intermediated finance ${ }^{4}$ we find that generically there is a mix of financing source in equilibrium, i.e. firms obtain finance from the bank as well as by issuing bonds. This prediction is confirmed by several empirical studies (see, for example, Houston and James, 1996, and Johnson, 1997). Moreover, our model can explain the stylized fact that bad risks receive more finance from the bank relative to the bond market than good risks. The reason is that in the presence of a riskless deposit contract, which is offered by the bank, the investors' demand for bonds increases with the expected return and decreases with the default risk of the bonds. In equilibrium the credit volume is equal to the capital required by the firms in excess over what they obtain on the bond market. Hence, the credit volume is decreasing in the expected return and increasing in the default risk. The latter result is consistent with the observation that the proportion of bank debt is increasing in credit risk (see, for example, James, 1987 and Johnson, 1997). ${ }^{5}$

In addition we obtain interesting results concerning the nature of the equilibrium (pooling or screening). If firms only differ in the success probability of their projects our model predicts that there will be a pooling equilibrium, whenever the proportion of high risk projects in the economy is small, and a screening equilibrium, whenever the proportion is large. In the latter case the low risks are driven out of the market. This is the classic adverse selection effect. If, on the contrary, firms only differ in the expected return of their projects, then there is pooling for small proportions of the "good" project (high expected return) while there is screening if its proportion in the economy is large. If there is screening we observe a positive selection effect, meaning that the low return project is driven out of the market. These results are very intuitive: If the proportion of firms that are able to pay a high interest rate on credit gets sufficiently large, it is optimal for the bank to violate the participation constraint for the firms with a low willingness to pay, i.e. we have a screening equilibrium. Since the firms' willingness to pay

\footnotetext{
${ }^{4}$ Notable exceptions are the papers by Besanko and Kanatas (1993) and Rajan (1992).

${ }^{5} \mathrm{We}$ are not aware of any empirical analysis that studies the influence of the project return on the financing source.
} 
is increasing in the expected return of the project and decreasing in the success probability we obtain the selection effects described above. These predictions have not been obtained by the previous literature and to our knowledge there is no empirical study that has compared the characteristics of projects that have been financed by bank debt with those that were refused a credit. Subject to the availability of detailed data on bank lending this would clearly be an interesting research topic.

Our paper is organized as follows. In section 2 we set up the model and derive first results concerning admissible contracts for the bank. The optimal contract for the bank is determined in section 3, where we also discuss some extensions of the model. We conclude the paper in section 4. All proofs are in the appendix.

\section{The Model}

There are three types of agents in our economy, investors, firms and a monopolistic bank. There are two periods $t=0,1$, and there is one good (capital) in each period. Firms seek finance for a risky project either at a bank or on the bond market and we explicitly allow for a mix of financing source. Each project has a fixed scale and requires an investment of one unit in $t=0$. The returns of the projects are realized in $t=1$. Investors are the only agents who possess funds in our economy. Thus, if the bank wants to give a credit to a firm, it first has to raise funds from the investors. The precise characteristics of the agents are as follows.

Investors: There is a continuum of identical investors with mass equal to 1. Each investor has an endowment of one unit (of capital) in $t=0$ and nothing in $t=1$. All consumption takes place at $t=1{ }^{6}$ Investors are risk-averse expected utility maximizers and their preferences for consumption in $t=1$ are represented by the von Neumann-Morgenstern utility function $u(x)=\ln (x)$ for $x>0 .{ }^{7}$ If

\footnotetext{
${ }^{6}$ That is, we assume that consumption in $t=0$ is already completed.

${ }^{7}$ The results of this paper are not specific to logarithmic utility functions. The same implications can be derived for the class of utility functions with constant relative risk aversion (CRRA) $\rho$ with $0<\rho \leq 1$ and $\rho$ sufficiently close to 1 . The essential property that we need to obtain the results of the paper is that the investment in the bond is increasing in the return it
} 
there is no bank and no bond market, any investor consumes her period zero endowment in $t=1$, i.e. we assume that there is a storage technology and that capital is non-perishable. ${ }^{8}$

Firms: There is a continuum of firms that are owned and run by managers who aim to maximize firms' expected profits at $t=1$. The mass of firms is 1 and hence equals the mass of investors. We can think of the firm as a start-up. The manager has a project idea but no financial resources to realize the fixed scale project, which requires an investment of one unit in $t=0$. The manager will only engage in the project if the expected profit covers his opportunity cost $K>0$. This participation constraint may, for example, reflect his opportunities to work as an employee for some other firm instead of starting his own business.

We distinguish firms by the quality of their projects which we measure along two dimensions, namely expected return and risk as reflected by the project's success probability (cf. Hellmann and Stiglitz, 2000). Hence, the type of a firm is given by $\theta=(\mu, \sigma)$ with $\mu \in \mathbb{R}_{+}, \sigma>1$, where $1 / \sigma$ is the success probability and $\mu$ is the expected return of the project. The return of a project with type $\theta=(\mu, \sigma)$ then is $Q(\theta):=\sigma \mu$ with probability $p(\theta):=1 / \sigma$ and 0 with probability $1-p(\theta)$. The distribution of project returns across firms with the same type $\theta$ is assumed to satisfy a law of large numbers, i.e. there is no aggregate risk. ${ }^{9}$ Moreover, we assume that the distribution of returns is independent across projects of different types.

There is asymmetric information concerning the type of a firm which is only known to the manager. Since the firm has no financial resources, collateral cannot serve as a screening device between different projects as in Bester (1985).

delivers in the no-default state. As is well known, CRRA utility functions with $0<\rho \leq 1$ have this property.

${ }^{8}$ This assumption could easily be relaxed to allow for a positive depreciation rate without any qualitative change of our results.

${ }^{9}$ Observe that there is no law of large numbers for a continuum of independent and identically distributed random variables (see Judd, 1985, and Feldman and Gilles, 1985). On the other hand, as Feldman and Gilles (1985) have shown, our distributional assumptions are innocuous. There is a continuum of random variables, which are identically distributed according to the distribution we have specified and which satisfy a law of large numbers. We merely have to abandon independence, which is not needed for our results. 
Managers are not subject to moral hazard, though, i.e. they cannot choose the quality of their project. Project returns are not publicly observable unless a firm does not repay its debt and is declared bankrupt. Thus, ex post verification of types is only possible in case of bankruptcy. We will come back to this point when we discuss credit contracts.

We will assume that there are two types of firms in the economy, $\theta^{1}=\left(\mu_{1}, \sigma_{1}\right)$ and $\theta^{2}=\left(\mu_{2}, \sigma_{2}\right)$, with corresponding proportions $\lambda>0$ and $1-\lambda>0$ that are common knowledge among all agents in the economy. Moreover, we assume that

$$
\mu_{i}-K>1 \text { for } i=1,2 \text {, }
$$

i.e. that it is strictly efficient to carry out both projects. In the following let $p_{i}=p\left(\theta^{i}\right)=1 / \sigma_{i}$ and $Q_{i}=Q\left(\theta^{i}\right)=\sigma_{i} \mu_{i}$ for $i=1,2$.

Bank: The bank has no financial resources in either period and has to obtain funds from investors in order to lend money to a firm. The bank is risk-neutral and aims to maximize its expected period 1 profit from lending to firms and borrowing from investors.

There are three assets that can be traded in our economy, a deposit contract, a credit contract and a bond. There is restricted participation in these markets and there are short selling constraints and buying floors which are different for the different agents in our economy. In our simple model some of these constraints cannot be obtained endogenously but they are exogenously justified.

Deposit Contract: A deposit contract is characterized by a safe return $r^{D} \geq 0$ which is independent of the state of the world that is realized in $t=1$, i.e. independent of the failure of any firm's project. Hence, $r^{D}-1$ is the interest rate on deposits. Only the bank and the investors are allowed to trade in the deposit contract and the bank is restricted to go short, while the investors are restricted to go long in this contract. We will see later that the deposit contract is indeed a safe asset, i.e. that the bank, by choosing interest rates and credit volumes appropriately, returns $r^{D}$ almost surely. 
Credit Contract (Private Debt): A credit contract delivers the return $r^{C} \geq 0$ in $t=1$ if the debtor has enough funds to fulfill his obligations. Hence, ${ }^{C} \mathrm{C}-1$ is the interest rate on credit. If the debtor does not repay the credit he has to declare himself bankrupt at no cost and the bankrupt's funds, if any, go to the creditor. Thus, there is limited liability on the part of the debtor. Under such a contractual arrangement the creditor has no incentive to declare himself bankrupt if he has enough funds to repay his debt. Hence, if $r^{C}$ does not exceed the project's return in the good state, a credit contract will always deliver $r^{C}$ or 0 depending on whether the project was successful or not. Observe that, as we already mentioned above, ex post verification of returns is not possible since there is no way to force a firm into bankruptcy unless it does not repay its credit. Hence, a standard debt contract (cf. Gale and Hellwig, 1985) is the only feasible contractual arrangement under limited liability and there is no way to screen the firms using this instrument without driving one firm out of the market.

We restrict the bank to go long and the firms to go short in the credit contract while investors are not allowed to trade in this contract.

Bond Contract (Public Debt): A bond contract is identical to a credit contract except for different restrictions on market participation. Firms are restricted to go short and investors are restricted to go long in the bond contract. For ease of presentation we do not allow the bank to trade in bonds. This assumption is innocuous since we would obtain the same results if the bank were active on the bond market. ${ }^{10}$ The risky return of the bond contract in $t=1$ is denoted by $r^{B} \geq 0$, i.e. $r^{B}-1$ is the interest an investor receives for one unit of bond if the project is successful.

The bank chooses the interest rate on deposits and on credit as well as the credit volume $C$, where $0 \leq C \leq 1$. In our model the bank does not set the

\footnotetext{
${ }^{10}$ It is straightforward to show that for any admissible contract (cf. Definition 2.1 and Definition 2.2) where the bank trades in bonds, there exists an admissible contract without trading activity of the bank on the bond market such that the bank's profit is the same. Hence, without loss of generality, we can restrict to admissible contracts, where the bank does not trade in bonds.
} 
deposit volume it is willing to accept, which again can be justified exogenously. ${ }^{11}$ All other agents act as price takers, i.e. investors take $r^{D}$ and $r^{B}$ as given and choose the optimal portfolio of deposits and bonds and firms take as given $r^{C}$ and $r^{B}$ and the credit volume $C$ and choose the optimal financing strategies for their projects. We will now analyze the optimization problems of the different agents.

Optimization problem of a firm: Let the firm be of type $\theta=(\mu, \sigma)$. Given $C, 0 \leq C \leq 1, r^{C} \geq 0, r^{B} \geq 0$, the firm chooses whether to participate or not and whether to accept the bank's offer or else obtain all finance for the project on the bond market. If $C \geq 0$ is the amount of credit the firm borrows from the bank and if $B \geq 0$ is the amount of bonds it sells on the bond market, then its expected period 1 profits are

$$
\Pi^{\theta}=\left\{\begin{array}{ll}
p(\theta) \max \left\{0, Q(\theta)-C r^{C}-B r^{B}\right\}, & \text { if } C+B \geq 1 \\
0 \quad & \text { else }
\end{array} .\right.
$$

The firm will only participate if the expected profits cover its opportunity cost, i.e. if $\Pi^{\theta} \geq K$. The profit maximizing choice of the firm is independent of its type and is given by

$$
C^{\theta}\left(C, r^{C}, r^{B}\right)=\left\{\begin{array}{ll}
C, & \text { if } r^{B} \geq r^{C} \\
0, & \text { else }
\end{array} \quad, \quad B^{\theta}\left(C, r^{C}, r^{B}\right)=1-C^{\theta}\left(C, r^{C}, r^{B}\right)\right.
$$

and the firm participates if and only if

$$
\begin{aligned}
p(\theta)\left(Q(\theta)-C^{\theta}\left(C, r^{C}, r^{B}\right) r^{C}-B^{\theta}\left(C, r^{C}, r^{B}\right) r^{B}\right) & \geq K \\
\Longleftrightarrow \quad \mu-p(\theta)\left(C^{\theta}\left(C, r^{C}, r^{B}\right) r^{C}+B^{\theta}\left(C, r^{C}, r^{B}\right) r^{B}\right) & \geq K .{ }^{12}
\end{aligned}
$$

Since each type of firm is interested in minimizing the repayment in the good state, $C^{\theta}\left(C, r^{C}, r^{B}\right) r^{C}+B^{\theta}\left(C, r^{C}, r^{B}\right) r^{B}$, and since this repayment is independent of the type, the bank cannot separate types by offering two different credit

\footnotetext{
${ }^{11}$ We have in mind standard savings deposits here.

${ }^{12}$ To be precise, the maximizer of the expected profit function is not unique if profits are never positive for the given $\left(C, r^{C}, r^{B}\right)$. However, in this case, the firm will not participate so there is no harm in selecting a particular maximizer then. Also, we assume that the firm accepts the bank's offer in case of indifference, i.e. whenever $r^{B}=r^{C}$. Introducing another tie breaking rule would not change our result qualitatively as long as each firm accepts the bank's offer with a positive probability if $r^{C}=r^{B}$.
} 
contracts $\left(C_{1}, r_{1}^{C}\right)$ and $\left(C_{2}, r_{2}^{C}\right)$ so that each contract is chosen by exactly one type. Indeed, if the bank would offer two different credit contracts $\left(C_{1}, r_{1}^{C}\right)$ and $\left(C_{2}, r_{2}^{C}\right)$, then either both types would choose the same offer, or both would obtain all finance on the bond market, or at least one type would not participate. Hence, the bank cannot do better than by offering exactly one contract and the only way it can separate the firms is by offering a credit contract that is acceptable to one type only.

Optimization problem of an investor: Each investor can invest in deposits, yielding the riskless return $r^{D}$, and in a bond, yielding the return $r^{B}$ unless the firm that issued the bond is bankrupt. If $r^{D}<1$, an investor will not invest into deposits but rather store her capital until period $1 .{ }^{13}$ Hence, the bank will never offer $r^{D}<1$ and we will only consider the case $r^{D} \geq 1$ in the following. The investor (knowing the firm's participation constraint) correctly anticipates that bankruptcy can only occur in case of a failure of the project. ${ }^{14}$ We assume that investors cannot diversify the risk at the bond market, i.e. there is no "pooling security" as in Bisin and Gottardi (1999) and investors cannot build a pooling bond by themselves, which is justified if pooling on a small scale is too costly. Hence, risk pooling is provided by the bank in our model while each investor buys bonds from one firm only. This assumption is crucial, but it can be considerably weakened. Our results can be extended to the case where investors can diversify their risk on the bond market to some extent as long as full diversification is not possible. However, the analysis becomes more complicated then without providing any new insights. Thus, for ease of presentation we assume that investors cannot diversify their risk on the bond market at all. This implies, in particular, that if both types of firms offer a bond, then chance determines whether an investor obtains a type $\theta^{1}$ or a type $\theta^{2}$ bond.

Given her belief $\beta$ about the proportion of type $\theta^{1}$ firms in the pool of firms offering a bond contract, and taking as given $r^{D} \geq 1$ and $r^{B} \geq 0$ each investor solves

\footnotetext{
${ }^{13}$ Recall that we assumed the depreciation rate to be zero.

${ }^{14}$ Recall from the optimization problem of a firm that it will only participate if expected profits exceed $K>0$, hence in equilibrium there is no bankruptcy in case of a success of the project.
} 


$$
\begin{gathered}
\max \quad \beta\left[\left(1-p_{1}\right) u\left(D r^{D}\right)+p_{1} u\left(D r^{D}+B r^{B}\right)\right] \\
+(1-\beta)\left[\left(1-p_{2}\right) u\left(D r^{D}\right)+p_{2} u\left(D r^{D}+B r^{B}\right)\right] \\
\text { s.t. } D, B \geq 0 \text { and } D+B \leq 1, \\
\quad \max \quad(1-\bar{p}(\beta)) u\left(D r^{D}\right)+\bar{p}(\beta) u\left(D r^{D}+B r^{B}\right) \\
\text { s.t. } D, B \geq 0 \text { and } D+B \leq 1,
\end{gathered}
$$

where $\bar{p}(\beta)=\beta p_{1}+(1-\beta) p_{2}$. Since $u(x)=\ln (x)$ is strictly monotone the investor optimally chooses $B=1-D$. From the first order condition, which is necessary and sufficient for a maximum since $u$ is strictly concave, we obtain

$$
D\left(\beta, r^{B}, r^{D}\right)=\left\{\begin{array}{ll}
(1-\bar{p}(\beta)) \frac{r^{B}}{r^{B}-r^{D}}, & \text { if } \bar{p}(\beta) r^{B} \geq r^{D} \\
1 & \text { else }
\end{array} .\right.
$$

Hence, each investor always invests in the riskless deposit contract and she also invests in the bond unless its expected return is smaller than the deposit return.

Admissible contracts for the bank: The bank is restricted to choose $\left(C, r^{C}, r^{D}\right)$ from a set of admissible contracts which can naturally be of two types, pooling or screening. While both firm types obtain finance at the same conditions in a pooling contract, a screening contract separates the firms so that only one type obtains finance while the other does not participate. As we have seen before, the latter is the only possibility to screen the firms. A contract is admissible if it induces an equilibrium in the economy. In particular, there must be market clearing on the bond market. The bank anticipates this equilibrium and chooses a contract such as to maximize its expected period 1 profits. 
Definition $2.1 A$ contract $\left(C, r^{C}, r^{D}\right)$ with $0 \leq C \leq 1$ and $r^{C} \geq 0, r^{D} \geq 1$, is an admissible pooling contract if there exists $r^{B} \geq 0$ and a belief $\beta$ such that

(i) $C^{\theta^{i}}\left(C, r^{C}, r^{B}\right)=C$ for $i=1,2$,

(ii) $\mu_{i}-p_{i}\left(C r^{C}+(1-C) r^{B}\right) \geq K$ for $i=1,2$,

(iii) $\beta=\lambda$,

(iv) $1-D\left(\beta, r^{B}, r^{D}\right)=1-C$.

Hence, $\left(C, r^{C}, r^{D}\right)$ is an admissible pooling contract if both types of firms participate and accept the contract (conditions (i) and (ii)), if the investors have correct beliefs concerning the proportion of type $\theta^{1}$ firms on the bond market (condition (iii)) and if there is market clearing on the bond market (condition (iv)). Observe that the market clearing condition on the bond market implies that $C=D\left(\beta, r^{B}, r^{D}\right)$, i.e. the bank obtains enough funds in order to give credit to the firms in period 0. The bank's expected profit at an admissible pooling contract $\left(C, r^{C}, r^{D}\right)$ then is given by

$$
\Gamma^{P}\left(C, r^{C}, r^{D}\right)=C\left(\bar{p}(\lambda) r^{C}-r^{D}\right)
$$

Given our assumption that there is no aggregate risk, $\Gamma^{P}\left(C, r^{C}, r^{D}\right)$ is equal to the average realized profit almost surely. Hence, whenever $\Gamma^{P}\left(C, r^{C}, r^{D}\right) \geq 0$, the bank fulfills the deposit contract almost surely.

As we have discussed before, in a screening contract one type of firm is driven out of the market.

Definition 2.2 A contract $\left(C, r^{C}, r^{D}\right)$ with $0 \leq C \leq 1$ and $r^{C} \geq 0, r^{D} \geq 1$, is an admissible screening contract if for some $i \in\{1,2\}$ there exists $r^{B} \geq 0$ and a belief $\beta$ such that

(i) $C^{\theta^{i}}\left(C, r^{C}, r^{B}\right)=C$,

(ii) $\mu_{i}-p_{i}\left(C r^{C}+(1-C) r^{B}\right) \geq K>\mu_{j}-p_{j}\left(C r^{C}+(1-C) r^{B}\right)$ for $j \neq i$, 


$$
\begin{aligned}
& \text { (iii) } \beta= \begin{cases}1 & , \text { if } i=1 \\
0, & \text { else }\end{cases} \\
& \text { (iv) } 1-D\left(\beta, r^{B}, r^{D}\right)=\left\{\begin{array}{ll}
\lambda(1-C) & , \text { if } i=1 \\
(1-\lambda)(1-C) & , \text { else }
\end{array}\right. \text {. }
\end{aligned}
$$

Thus, $\left(C, r^{C}, r^{D}\right)$ is an admissible screening contract if it is only accepted by a firm of type $\theta^{i}$, while type $\theta^{j}$ 's participation constrained is violated (conditions (i) and (ii)), if the investors have correct beliefs concerning the proportion of type $\theta^{1}$ firms on the bond market (condition (iii)) and if there is market clearing on the bond market (condition (iv)). Again the market clearing condition on the bond market implies that the bank gets enough deposits in order to give credit to firms in period 0: If $\beta$ is the corresponding correct belief of the investors, then

$$
D\left(\beta, r^{B}, r^{D}\right)-\beta \lambda C-(1-\beta)(1-\lambda) C=1-\beta \lambda-(1-\beta)(1-\lambda)>0 .
$$

The bank invests the amount of deposits that exceeds the credit volume in the storage technology so that its expected profit at an admissible screening contract $\left(C, r^{C}, r^{D}\right)$ is given by

$$
\begin{aligned}
\Gamma^{S}\left(C, r^{C}, r^{D}\right)= & {\left[\beta \lambda p_{1}+(1-\beta)(1-\lambda) p_{2}\right] C r^{C}+1-\beta \lambda-(1-\beta)(1-\lambda) } \\
& -D\left(\beta, r^{B}, r^{D}\right) r^{D} .
\end{aligned}
$$

If $\left(C, r^{C}, r^{D}\right)$ is an admissible pooling (screening) contract and if $r^{B} \geq 0$ is a corresponding equilibrium interest factor on the bond market (see Definitions 2.1 and 2.2), then we will call $r^{B}$ an interest factor on bonds supporting the pooling (screening) contract $\left(C, r^{C}, r^{D}\right)$. We will show below that the interest factor $r^{B}$ supporting an admissible pooling or an admissible screening contract is uniquely determined if the bank's profit at this contract is nonnegative. However, in general, it is possible that $\left(C, r^{C}, r^{D}\right)$ is an admissible pooling as well as an admissible screening contract, i.e. that there are two possible equilibria on the bond market each corresponding to a different belief of the investors. In this case there exist $r^{B}, \tilde{r}^{B}$ with $r^{B} \neq \tilde{r}^{B}$, such that $r^{B}$ supports $\left(C, r^{C}, r^{D}\right)$ as a pooling contract and $\tilde{r}^{B}$ supports $\left(C, r^{C}, r^{D}\right)$ as a screening contract as in the following example. 
Example 2.1 Let $\theta^{1}=(11,4)$ and $\theta^{2}=(11,4 / 3)$, i.e. both projects have the same expected return $\mu=11$, but project 1 is riskier than project 2 since $p_{1}=$ $1 / 4<p_{2}=3 / 4$. Moreover, let $\lambda=0.5$ and $K=1$. Then $\left(C, r^{C}, r^{D}\right)$ with $C=20 / 37, r^{C}=40 / 3$ and $r^{D}=1$ is an admissible pooling and an admissible screening contract: $r^{B}=r^{C}$ supports $\left(C, r^{C}, r^{D}\right)$ as a pooling contract and $\tilde{r}^{B}=$ 38 supports $\left(C, r^{C}, r^{D}\right)$ as a screening contract. We observe that $\Gamma^{P}\left(C, r^{C}, r^{D}\right)=$ $340 / 111>\Gamma^{S}\left(C, r^{C}, r^{D}\right)=70 / 111$.

We will see later under which conditions this multiplicity of equilibria can be ruled out. There is also another possible type of multiplicity of equilibria on the bond market: Let $\left(C, r^{C}, r^{D}\right)$ be an admissible contract with $C>0$. Then we would like to rule out a market clearing interest rate factor $\hat{r}^{B}$ on the bond market such that $\hat{r}^{B}<r^{C}$. If such an interest rate factor $\hat{r}^{B}$ would exist, the bank could not be sure which equilibrium would arise: the one with the interest rate factor $r^{B} \geq r^{C}$ that supports $\left(C, r^{C}, r^{D}\right)$ as a pooling or screening contract or the interest rate factor $\hat{r}^{B}$ which would lead to a closing down of the credit market. The following lemma shows that this problem will never arise.

Lemma 2.1 Let $\left(C, r^{C}, r^{D}\right)$ be an admissible pooling or screening contract with $C>0$. Then there exists no $\hat{r}^{B}<r^{C}$ that clears the bond market.

In the following we make some simple observations concerning the characteristics of admissible pooling and screening contracts.

\section{Lemma 2.2}

(i) Let $\left(C, r^{C}, r^{D}\right)$ be an admissible pooling contract with $\Gamma^{P}\left(C, r^{C}, r^{D}\right) \geq 0$. Let $\beta$ be the corresponding belief and $r^{B}$ the corresponding interest rate factor on the bond market supporting $\left(C, r^{C}, r^{D}\right)$. Then it is true that

$$
C>0, r^{B} \geq r^{C} \text { and } \quad \bar{p}(\beta) r^{C} \geq r^{D}
$$

where $\bar{p}(\beta)=\beta p_{1}+(1-\beta) p_{2}$. 
(ii) Let $\left(C, r^{C}, r^{D}\right)$ be an admissible screening contract with $\Gamma^{S}\left(C, r^{C}, r^{D}\right) \geq 0$. Let $\beta$ be the corresponding belief and $r^{B}$ the corresponding interest rate factor on the bond market supporting $\left(C, r^{C}, r^{D}\right)$. If $C>0$, then

$$
\bar{p}(\beta) r^{C} \geq r^{D} \text { and } r^{B} \geq r^{C}
$$

where $\bar{p}(\beta)$ is defined as above.

The next lemma shows that the interest factor on bonds supporting an admissible contract as a pooling, respectively screening contract, is uniquely determined if the bank's profit is nonnegative.

Lemma 2.3 Let $\left(C, r^{C}, r^{D}\right)$ be an admissible pooling, respectively screening contract with $\Gamma^{P}\left(C, r^{C}, r^{D}\right) \geq 0$, respectively $\Gamma^{S}\left(C, r^{C}, r^{D}\right) \geq 0$. Let $r^{B}$ and $\hat{r}^{B}$ be two interest factors on bonds, both supporting the contract $\left(C, r^{C}, r^{D}\right)$ as a pooling, respectively screening contract. Then $r^{B}=\hat{r}^{B}$.

\section{The Optimal Contract for the Bank}

In the following we will determine the optimal contract for the bank. We start by observing that for a profit maximizing contract $\left(C, r^{C}, r^{D}\right)$ with $C>0$ it must be true that $r^{B}=r^{C}$, where $r^{B}$ is the interest rate factor on the bond market supporting $\left(C, r^{C}, r^{D}\right)$. This result is rather intuitive because if $r^{B}>r^{C}$, then the bank can increase its profit by slightly increasing both the credit volume and the interest rate on credit, leaving the firms' profits unaffected. We state this fact in the following lemma.

Lemma 3.1 Let $\left(C, r^{C}, r^{D}\right)$ be an admissible pooling (screening) contract and let $r^{B}$ support $\left(C, r^{C}, r^{D}\right)$ as a pooling (screening) contract. Moreover, let $\Gamma^{P}\left(C, r^{C}, r^{D}\right) \geq 0\left(\Gamma^{S}\left(C, r^{C}, r^{D}\right)>0\right)$. If $r^{B}>r^{C}$, then there exists an admissible pooling (screening) contract $\left(\hat{C}, \hat{r}^{C}, \hat{r}^{D}\right)$ such that

$$
\Gamma^{P}\left(\hat{C}, \hat{r}^{C}, \hat{r}^{D}\right)>\Gamma^{P}\left(C, r^{C}, r^{D}\right) \quad\left(\Gamma^{S}\left(\hat{C}, \hat{r}^{C}, \hat{r}^{D}\right)>\Gamma^{S}\left(C, r^{C}, r^{D}\right)\right) .
$$


In order to determine the profit maximizing contract for the bank we proceed in two steps. First, we determine the optimal pooling and the optimal screening contract ignoring the possibility of multiple equilibria on the bond market. Afterwards we give conditions under which there is a unique equilibrium on the bond market and we analyze whether the optimal pooling or the optimal screening contract maximizes the bank's profits. The profit maximizing pooling contract solves

$$
\begin{aligned}
& \operatorname{Max}_{C, r^{C}, r^{D}} \quad \Gamma^{P}\left(C, r^{C}, r^{D}\right) \\
& \text { s.t. }\left(C, r^{C}, r^{D}\right) \text { is an admissible pooling contract. }
\end{aligned}
$$

We can restrict to those admissible pooling contracts that give the bank nonnegative profits. ${ }^{15}$ Then, by Lemma 2.2 and Lemma 3.1 we know that $r^{B}=r^{C}$, if $r^{B}$ supports the profit maximizing pooling contract $\left(C, r^{C}, r^{D}\right)$. Hence, the profit maximizing pooling contract for the bank is a solution to the following optimization problem:

$$
\begin{aligned}
& \quad \operatorname{Max}_{r^{C}, r^{D}} \quad F^{P}\left(r^{C}, r^{D}\right):=(1-\bar{p}(\lambda)) \frac{r^{C}}{r^{C}-r^{D}}\left(\bar{p}(\lambda) r^{C}-r^{D}\right) \\
& (P) \quad \text { s.t. } \bar{p}(\lambda) r^{C} \geq r^{D} \geq 1 \text { and } \\
& \quad r^{C} \leq \min _{i=1,2}\left\{\sigma_{i}\left(\mu_{i}-K\right)\right\}
\end{aligned}
$$

Since $F^{P}$ is decreasing in $r^{D}$ and increasing in $r^{C}$ we get the following result.

Theorem 3.1 (Profit Maximizing Pooling Contract) Let $\theta^{1}=\left(\mu_{1}, \sigma_{1}\right)$ and $\theta^{2}=\left(\mu_{2}, \sigma_{2}\right)$. Then, there exists a solution to the bank's optimization problem (P) if and only if

$$
\bar{p}(\lambda) \min _{i=1,2}\left\{\sigma_{i}\left(\mu_{i}-K\right)\right\} \geq 1 .
$$

If this condition is satisfied, the solution to $(P)$ is given by $\left(\hat{r}^{C}, \hat{r}^{D}\right)$ with

$$
\hat{r}^{C}=\min _{i=1,2}\left\{\sigma_{i}\left(\mu_{i}-K\right)\right\}, \hat{r}^{D}=1
$$

\footnotetext{
${ }^{15}$ If all admissible contracts give negative expected profits the bank will not participate and hence receive zero profits.
} 
and the profit maximizing pooling contract is given by $\left(\hat{C}, \hat{r}^{C}, \hat{r}^{D}\right)$, with

$$
\hat{C}=(1-\bar{p}(\lambda)) \frac{\hat{r}^{C}}{\hat{r}^{C}-1} .
$$

There is trade on the bond market, i.e. $\hat{C}<1$, if and only if $\bar{p}(\lambda) \hat{r}^{C}>1$.

If we number types such that $\sigma_{1}\left(\mu_{1}-K\right) \geq \sigma_{2}\left(\mu_{2}-K\right)$, we see that in the profit maximizing pooling contract all rents from a type $\theta^{2}$ firm but not necessarily all rents from a type $\theta^{1}$ firm are absorbed. However, in general, not all rents go to the bank. They are partly taken by the investors, since $\hat{C}=1$ if and only if $\bar{p}(\lambda) \min _{i=1,2}\left\{\sigma_{i}\left(\mu_{i}-K\right)\right\}=1$. Hence, generically, the bank's preference for high interest rates on credit will lead to the emergence of a bond market which is rather intuitive: Given the preferences of the investors the bond market will close down only if the interest rate on this market is very low. Since the interest rate on bonds is positively correlated with the interest rate on credit (in fact they are the same if the contract is chosen optimally) the bank has to put up with the coexistence of the bond market if it wants keep interest rates high.

Next we determine the profit maximizing screening contract. The bank solves

$$
\begin{aligned}
& \operatorname{Max}_{C, r^{C}, r^{D}} \quad \Gamma^{S}\left(C, r^{C}, r^{D}\right) \\
& \text { s.t. }\left(C, r^{C}, r^{D}\right) \text { is an admissible screening contract. }
\end{aligned}
$$

Let $\theta^{1}=\left(\mu_{1}, \sigma_{1}\right), \theta^{2}=\left(\mu_{2}, \sigma_{2}\right)$ be such that

$$
\sigma_{1}\left(\mu_{1}-K\right)>\sigma_{2}\left(\mu_{2}-K\right)
$$

If $\theta^{1}, \theta^{2}$, do not satisfy this condition (possibly after renumbering), there does not exist an admissible screening contract since condition (ii) in Definition 2.2 is always violated. Hence, w.l.o.g. we will assume that the type $\theta^{2}$ firm will drop out of the market if there is screening. This implies $\beta=1$ for the correct belief of the investors.

In order to rule out multiple equilibria on the bond market we will later restrict the parameters of our model such that the best pooling contract always 
gives positive profits to the bank. Hence, in our search for a profit maximizing screening contract we can restrict to those contracts that give positive expected profits to the bank. By appealing to Lemma 2.2 and Lemma 3.1 we find the profit maximizing screening contract as a solution to the following optimization problem:

$$
\begin{aligned}
& \operatorname{Max}_{r^{C}, r^{D}} F^{S}\left(r^{C}, r^{D}\right):=\left(1-p_{1}\right) \frac{r^{C}}{r^{C}-r^{D}}\left(p_{1} r^{C}-r^{D}\right)+(1-\lambda)\left(1-p_{1} r^{C}\right) \\
& \text { s.t. } p_{1} r^{C} \geq r^{D} \geq 1 \text { and } \\
& \sigma_{1}\left(\mu_{1}-K\right) \geq r^{C}>\sigma_{2}\left(\mu_{2}-K\right) .
\end{aligned}
$$

We obtain the following result.

Theorem 3.2 (Profit Maximizing Screening Contract) Let $\theta^{1}=\left(\mu_{1}, \sigma_{1}\right)$ and $\theta^{2}=\left(\mu_{2}, \sigma_{2}\right)$ be such that $\sigma_{1}\left(\mu_{1}-K\right)>\sigma_{2}\left(\mu_{2}-K\right)$, and let

$$
\tilde{r}^{C}=\left\{\begin{array}{ll}
\sigma_{1}\left(\mu_{1}-K\right) & , \text { if } \lambda \geq p_{1} \\
\min \left\{1+\frac{1-p_{1}}{\sqrt{p_{1}\left(p_{1}-\lambda\right)}}, \sigma_{1}\left(\mu_{1}-K\right)\right\}, & \text { else }
\end{array} .\right.
$$

If $\tilde{r}^{C}>\sigma_{2}\left(\mu_{2}-K\right)$, then the solution to $(S)$ is given by $\left(\tilde{r}^{C}, \tilde{r}^{D}\right)$ with $\tilde{r}^{D}=1$. In this case the profit maximizing screening contract is $\left(\tilde{C}, \tilde{r}^{C}, \tilde{r}^{D}\right)$ with

$$
\tilde{C}=\frac{1}{\lambda}\left(\left(1-p_{1}\right) \frac{\tilde{r}^{C}}{\tilde{r}^{C}-1}-(1-\lambda)\right)<1
$$

and it yields strictly positive profits for the bank.

If $\tilde{r}^{C} \leq \sigma_{2}\left(\mu_{2}-K\right)$, then there exists no profit maximizing screening contract.

Again the bank's profits are decreasing in $r^{D}$ so that it is optimal for the bank to set $\tilde{r}^{D}=1$. However, contrary to the case of a pooling contract, profits are not necessarily increasing in $r^{C}$ over the whole domain. Hence, the bank may maximize profits at an intermediate interest rate on credit and the type $\theta^{1}$ firm gets a positive rent. This will be the case if $\lambda$ is sufficiently small. Then, the increase in profit due to the increase in $r^{C}$ is too small to compensate for the 
decrease in the credit volume and hence the decrease in profit that is caused by the reduction in the investors' demand for deposits. If at the intermediate interest rate the type $\theta^{2}$ firm would enter the market as well, there exists no profit maximizing screening contract since the bank would like to charge an interest rate factor $r^{C}$ arbitrary close to $\sigma_{2}\left(\mu_{2}-K\right)$ in this case. Finally, we observe that, whenever there exists a profit maximizing screening contract, then there is trade on the bond market.

We now come back to the problem of multiplicity of equilibria on the bond market. Obviously, the profit maximizing screening contract $\left(\tilde{C}, \tilde{r}^{C}, \tilde{r}^{D}\right)$ can never be an admissible pooling contract: Any admissible pooling contract has to satisfy $C>0$. If $\tilde{r}^{B}$ is the interest rate factor on bonds supporting $\left(\tilde{C}, \tilde{r}^{C}, \tilde{r}^{D}\right)$ as a screening contract, then any $\hat{r}^{B}$ supporting this contract as a pooling contract would have to satisfy $\hat{r}^{B}>\tilde{r}^{C}=\tilde{r}^{B}$ since the firms accept $\hat{C}>0$ only if $\hat{r}^{B} \geq \tilde{r}^{C}$. However, if $\hat{r}^{B}>\tilde{r}^{C}=\tilde{r}^{B}$, then the participation constraint of the type $\theta^{2}$ firm is violated. On the contrary, Example 2.1 shows that the profit maximizing pooling contract can be an admissible screening contract. ${ }^{16}$ If the bank proposes this contract it may turn out that the resulting equilibrium on the bond market leads to screening and gives the bank a lower profit than the best pooling contract. In this case it is difficult to predict the bank's behavior. Under a pessimistic attitude the bank will never propose a pooling contract if this may result in a screening equilibrium giving the bank a lower profit than the pooling equilibrium. On the contrary, if the bank is optimistic, it will act as if there were no multiplicity of equilibria believing that the pooling equilibrium will arise. Since it is not clear whether one should assume an optimistic or pessimistic attitude on the part of the bank we look for conditions on the parameters of our model under which there exists a unique equilibrium on the bond market. The following lemma provides such conditions.

\footnotetext{
${ }^{16}$ Observe that the contract in Example 2.1 is indeed the profit maximizing pooling contract for the given parameters.
} 
Lemma 3.2 Let $\theta^{1}=\left(\mu_{1}, \sigma_{1}\right)$ and $\theta^{2}=\left(\mu_{2}, \sigma_{2}\right)$ be given with $\sigma_{1}\left(\mu_{1}-K\right)>$ $\sigma_{2}\left(\mu_{2}-K\right)$. Let $\left(\hat{C}, \hat{r}^{C}, \hat{r}^{D}\right)$ be a profit maximizing pooling contract such that $\Gamma^{P}\left(\hat{C}, \hat{r}^{C}, \hat{r}^{D}\right) \geq 0$. If

$$
\sigma_{1}=\sigma_{2} \quad \text { or } \quad \sigma_{1} \leq 2 \sigma_{2} \frac{\mu_{2}-K}{\mu_{2}-K+1}
$$

then $\left(\hat{C}, \hat{r}^{C}, \hat{r}^{D}\right)$ is not an admissible screening contract.

The conditions in (1) are not only sufficient but also necessary to rule out the multiplicity of equilibria for all $\lambda$ for which the profit maximizing pooling contract gives the bank a nonnegative profit. This is shown by the next lemma (see also Example 2.1 where both conditions in (1) are violated).

Lemma 3.3 Let $\theta^{1}=\left(\mu_{1}, \sigma_{1}\right)$ and $\theta^{2}=\left(\mu_{2}, \sigma_{2}\right)$ be given with $\sigma_{1}\left(\mu_{1}-K\right)>$ $\sigma_{2}\left(\mu_{2}-K\right)$ and let

$$
\sigma_{1} \neq \sigma_{2} \quad \text { and } \quad \sigma_{1}>2 \sigma_{2} \frac{\mu_{2}-K}{\mu_{2}-K+1} .
$$

If for some $\lambda>0$ there exists a profit maximizing pooling contract $\left(C, r^{C}, r^{D}\right)$ with $\Gamma^{P}\left(C, r^{C}, r^{D}\right) \geq 0$, then there exists $\hat{\lambda}>0$ such that the corresponding profit maximizing pooling contract $\left(\hat{C}, \hat{r}^{C}, \hat{r}^{D}\right)$ yields nonnegative profits and is also an admissible screening contract.

In the following we will assume that one of the conditions in (1) is fulfilled so that there is a unique equilibrium on the bond market. Let $\theta^{1}=\left(\mu_{1}, \sigma_{1}\right), \theta^{2}=$ $\left(\mu_{2}, \sigma_{2}\right)$ be given with $\sigma_{1}\left(\mu_{1}-K\right)>\sigma_{2}\left(\mu_{2}-K\right)$ and let $\alpha_{1}=\mu_{1}-K$ and $\alpha_{2}=\mu_{2}-K$. From Theorem 3.1 and Theorem 3.2 we recall that

$$
\stackrel{*}{\Gamma}^{P}(\lambda)=(1-\bar{p}(\lambda)) \frac{\alpha_{2}}{\alpha_{2}-p_{2}}\left(\frac{\bar{p}(\lambda)}{p_{2}} \alpha_{2}-1\right)
$$

is the profit from the best pooling contract whenever this profit is nonnegative and

$$
\stackrel{*}{\Gamma}^{S}(\lambda)=\left(p_{1} \tilde{r}^{C}-1\right)\left(\left(1-p_{1}\right) \frac{\tilde{r}^{C}}{\tilde{r}^{C}-1}-(1-\lambda)\right)
$$


is the profit from the best screening contract whenever $\tilde{r}^{C}>\sigma_{2} \alpha_{2}$, where

$$
\tilde{r}^{C}=\left\{\begin{array}{l}
\sigma_{1} \alpha_{1} \\
\min \left\{1+\frac{1-p_{1}}{\sqrt{p_{1}\left(p_{1}-\lambda\right)}}, \sigma_{1} \alpha_{1}\right\}, \text { else }
\end{array}\right.
$$

Moreover, from the proof of Theorem 3.2 we know that ${ }^{*} S(\lambda)$ gives an upper bound for the profit from a screening contract even if there exists no profit maximizing screening contract, i.e. if $\tilde{r}^{C} \leq \sigma_{2} \alpha_{2}$. Comparing $\stackrel{*}{\Gamma}^{S}(\lambda)$ with $\stackrel{*}{\Gamma}^{P}(\lambda)$ then gives the main result of our paper:

Theorem 3.3 (Optimal Contract) Let $\theta^{1}=\left(\mu_{1}, \sigma_{1}\right)$ and $\theta^{2}=\left(\mu_{2}, \sigma_{2}\right)$ be given with $\sigma_{1}\left(\mu_{1}-K\right)>\sigma_{2}\left(\mu_{2}-K\right)$.

(i) If $\sigma_{1}=\sigma_{2}$, then there exists $0<\lambda^{*}<1$ such that the bank's profits are maximized at the profit maximizing pooling contract for $\lambda \leq \lambda^{*}$ and at the profit maximizing screening contract for $\lambda \geq \lambda^{*}$.

(ii) If $\sigma_{1} \neq \sigma_{2}$ and $\sigma_{1} \leq 2 \sigma_{2} \frac{\mu_{2}-K}{\mu_{2}-K+1}$, then there exists $0<\lambda^{*}<1$ such that the bank's profits are maximized at the profit maximizing pooling contract for $\lambda \leq \lambda^{*}$ and at a screening contract for $\lambda \geq \lambda^{*}$. If $\mu_{1}-K>1$ is sufficiently small, then for all $\lambda \geq \lambda^{*}$ there exists a profit maximizing screening contract.

The profit maximizing pooling and screening contracts are the contracts defined in Theorem 3.1 and Theorem 3.2, respectively.

The theorem shows that the bank optimally chooses a pooling contract whenever the proportion of type $\theta^{1}$ firms is small while it optimally chooses a screening contract whenever their proportion is large. Under a screening contract type $\theta^{2}$ firms drop out of the market and only type $\theta^{1}$ firms obtain finance. This result is very intuitive. From our assumption that $\sigma_{1}\left(\mu_{1}-K\right)>\sigma_{2}\left(\mu_{2}-K\right)$ it follows that type $\theta^{1}$ firms are willing to pay a higher interest than type $\theta^{2}$ firms. Hence, if the proportion of type $\theta^{1}$ firms is large, it pays to contract with these firms 
only by asking for an interest rate on credit that is too high for the type $\theta^{2}$ firms. On the contrary, if the proportion of type $\theta^{1}$ firms is small it is better to keep interest rates low and contract with all firms. Clearly, the details that lead to this result are more involved as can be seen from the proof of Theorem 3.3 but the main mechanism is the one described before.

As we have seen it is always the firm with the lower willingness to pay that is driven out of the market under a screening contract. Since a firm's willingness to pay is given by $\sigma_{i}\left(\mu_{i}-K\right)$ there is a trade-off between the success probability and the expected return that determines which firm is driven out of the market. Hence, it is not clear whether the better or lower quality project obtains finance, i.e. whether we have a positive or an adverse selection effect. Let us consider two interesting extreme cases.

The case $\mu_{1}>\mu_{2}, \sigma_{1}=\sigma_{2}$ : In this case the return distribution of type $\theta^{1}$ 's project dominates the one of type $\theta^{2}$ 's project in the sense of first order stochastic dominance. Since the repayment probability is the same for both projects but type $\theta^{1}$ 's project delivers a higher expected return, firms with the high return project are willing to pay a higher interest rate on credit than firms with the low return project. Hence, there is a positive selection effect: We observe screening if the proportion of good projects (high expected return) is large, in which case the firms with low return projects drop out of the market.

The case $\mu_{1}=\mu_{2}, \sigma_{1}>\sigma_{2}$ : In this case the return of type $\theta^{1}$ 's project is a mean preserving spread of the return of type $\theta^{2}$ 's project, i.e. the return distribution of type $\theta^{2}$ dominates the one of type $\theta^{1}$ in the sense of second order stochastic dominance. Since both projects have the same expected return but type $\theta^{1}$ has a lower success and hence repayment probability than type $\theta^{2}$, firms with the high risk project (type $\theta^{1}$ ) are willing to pay a higher interest rate on credit than firms with the low risk project (type $\theta^{2}$ ). Hence, there is an adverse selection effect: If the proportion of high risk projects is large, there is screening and the low risks drop out of the market. 
In addition to the selection effects described above our results show that lower quality projects obtain more capital from the bank relative to the bond market than higher quality projects. From Theorem 3.3 and the characteristics of the optimal screening and pooling contracts we obtain the following comparative statics results. $^{17}$

(i) In the region where pooling is the optimal choice for the bank $\left(\lambda<\lambda^{*}\right)$, the credit volume is increasing in the risk of type $\theta^{1}$ 's project and it is decreasing in the expected return of type $\theta^{2}$ 's project. ${ }^{18}$ Moreover, the credit volume is increasing in the proportion of the project with the higher risk, i.e. if $\sigma_{1}>\sigma_{2}$, then the credit volume is increasing in $\lambda$, and if $\sigma_{1}<\sigma_{2}$, then the credit volume is increasing in $1-\lambda$.

(ii) In the region where screening is the optimal choice for the bank $\left(\lambda \geq \lambda^{*}\right)$ and where $\mu_{1}-K$ is sufficiently small the credit volume is increasing in the risk of the financed project and decreasing in its expected return. Also, the credit volume is increasing in the proportion of the financed project. Hence, if the financed project is the riskier one, then the bank allocates more capital to this project if its proportion in the economy increases.

Hence, in a nutshell, the higher the risk of a project or the lower its expected return, the more capital it obtains from the bank relative to the bond market. The intuition for this result is very simple: The lower the expected return of a project, the lower the interest rate on credit and bonds a firm is willing to pay. In the presence of a riskless deposit contract a low interest rate on bonds decreases the investors' demand for bonds and hence increases the credit volume by the market clearing condition. Similarly, a higher default risk on bonds decreases the investors' demand for bonds and therefore increases the credit volume. We have seen that the bank's preference for lower quality projects does not only concern the credit volume but also the type of contract (pooling or screening) that is chosen. Even though there can be a positive selection effect, where the low

\footnotetext{
${ }^{17}$ We have to restrict to local statements since we do not know how the credit volume in the optimal pooling contract compares to the one in the optimal screening contract at the threshold $\lambda^{*}$, where we have a change of regimes from pooling to screening.

${ }^{18}$ Observe that the credit volume is independent of the expected return of project 1.
} 
return project does not obtain finance, this positive selection is easily turned into an adverse selection if the risk of the low return project becomes sufficiently large. To see this observe that if $\mu_{1}<\mu_{2}$ and $\sigma_{1}$ is sufficiently large compared to $\sigma_{2}$, then type $\theta^{2}$ is driven out of the market. Thus, overall our results confirm the stylized fact that bad risks obtain more finance from banks relative to bond markets than good types. Our findings are natural in a context where a risk neutral bank has to raise funds from risk averse investors whose demand for the safe deposit increases with the riskiness of the bond and decreases with its return. This effect is not captured in partial equilibrium models where it is usually assumed that banks face an infinitely elastic supply of funds by investors at some exogenously given interest rate. In our model the supply of funds varies with the types of firms seeking finance on the bond and credit market and the bank takes this into account when setting the credit volume and the interest rates. Hence, our approach offers a new explanation for the stylized fact mentioned above and this is the risk aversion of investors.

Observe that, by definition, in our model there is no credit rationing in equilibrium (cf. Stiglitz and Weiss, 1981). If at the given interest rates for a bank credit and for bonds a firm is willing to obtain finance its demand is satisfied. Even if the bank does not offer to finance the whole project, the remaining funds can be raised on the competitive bond market, where interest rates adjust such that demand equals supply.

\subsection{Competitive Banking Sector}

Although there is some empirical evidence of monopoly power at the level of individual banks (see Cosimano and McDonald, 1998) it is important to note that the results obtained in this paper are not driven by the monopoly power of the bank. A full analysis of the competitive case clearly goes beyond the scope of this paper. Nevertheless, we want to indicate why our results are quite robust with respect to changes in the degree of competition in the banking sector.

Consider the case where there is competition between two banks. Obviously, in equilibrium both banks must make zero profits. Moreover, since banks compete for funds, the equilibrium interest rate on deposits will be maximal subject to the 
participation constraints of the firms and the zero profit condition of the banks. Hence, in a pooling equilibrium the maximal interest rate factor that banks can pay is given by $r^{* D}=\bar{p}(\lambda) \sigma_{2}\left(\mu_{2}-K\right)$ since $r^{* C}=\sigma_{2}\left(\mu_{2}-K\right)$ is the maximal interest rate factor on credit that type $\theta^{2}$ firms are willing to pay. One can show that banks can pay a higher interest rate on deposits under pooling than under screening if $\lambda$ is small. For $\lambda$ large screening allows for a higher interest rate than pooling. Hence, we obtain the same selection effects as in the monopoly case: for $\lambda$ small there will be a pooling equilibrium and for $\lambda$ large there will be a screening equilibrium.

Concerning changes in the credit volume with respect to changes in risk and return of the financed projects we first observe that there is no trade on the bond market if the economy is in a pooling equilibrium. This follows from the fact that investors invest all their capital at the bank if $r^{* D}=\bar{p}(\lambda) r^{* B} \cdot{ }^{19}$ Hence, in a pooling equilibrium firms obtain all their finance from the bank and the credit volume is invariant with respect to changes in risk and return. In case of a screening equilibrium, however, there is trade on the bond market. For the same reason as in the monopoly case the credit volume is decreasing in the expected return and increasing in the proportion of the financed project. Moreover, for a broad range of parameters the credit volume is increasing in the risk of the financed projects.

\subsection{Screening of Projects}

In our model firms have no capital, so that the bank can only use interest rates to screen the projects. As we have seen, in this case screening necessarily drives one firm type out of the market. In the following we briefly discuss the effect of introducing internal firm capital which allows for collateral to be used as an additional contractual instrument for screening projects. We will provide an informal and intuitive argument for why we expect that the main insight of our benchmark model remains true in this extended model, namely that lower quality projects receive more finance from the bank relative to the bond market

\footnotetext{
${ }^{19} \mathrm{As}$ in the monopolistic bank case one can show that in equilibrium the interest rate on bonds equals the interest rate on credit, i.e. $r^{* B}=r^{* C}$.
} 
than higher quality projects.

Consider a situation, where firms have some capital $A>0$ which is not sufficient to self-finance the project, i.e. $A<1$. For simplicity suppose that firms differ only with respect to the success probability of their projects, i.e. there is a high risk and a low risk type with success probability $1 / \sigma_{H}$ and $1 / \sigma_{L}$, respectively, where $\sigma_{H}>\sigma_{L}$. In addition to setting the credit volume and interest rate on credit the bank can now ask for a collateral $S \in[0, A]$ to be paid in case the financed project is not successful. Clearly, with a positive collateral for bank credit the interest rate on bonds has to be larger than the interest rate on credit. Otherwise firms would obtain all finance from the bond market. Also, the high risk type firm suffers more from an increase in collateral than the low risk type firm and hence, for any given credit volume, the high risk firm requires a larger decrease in the interest rate on credit than the low risk firm for any marginal increase in collateral. Suppose now that the bank offers the same contract $\left(S, C, r^{C}\right)$ to all firms. Then it can improve by offering an additional contract $\left(S^{H}, C, r^{C H}\right)$ with $S^{H}<S$ and $r^{C H}>r^{C}$ which will be preferred to the original contract by the high risk type only. Then, in order to satisfy the market clearing condition on the bond market, the bank has to increase the credit volume it offers to the high risk firm, i.e. $C^{H}>C$. To see this observe that a decrease in collateral decreases the supply of bonds. One way to restore market clearing then is to increase the credit volume for the high risk type which further decreases the supply for bonds but at the same time lowers the default risk on the bond market and hence increases the demand for bonds. Given these observations we conjecture that the bank maximizes profits by offering a menu of separating contracts $\left(S^{H}, C^{H}, r^{C H}\right),\left(S^{L}, C^{L}, r^{C L}\right)$ with $S^{H}<S^{L}, C^{H}>C^{L}$ and $r^{C H}>r^{C L}$ such that the high risk type chooses the contract with low collateral, large credit volume and large interest rate, while the low risk type prefers the contract with high collateral, small credit volume and low interest rate. Moreover, we conjecture that the total credit volume is decreasing in the expected return of the projects (which is assumed to be the same for both firm types) for the same reason as in our benchmark model: An increase in the expected return allows for higher interest rates on credit which will drive up the interest rate on bonds and hence increases the demand for bonds. Market clearing then requires that the credit 
volume must decrease.

Summarizing, as in our benchmark model without internal firm capital we expect to see more bank finance relative to the bond market for high risk and low return projects. A rigorous analysis which requires more subtle arguments than the ones we have provided above is left for future research.

\section{Conclusion}

We have presented a simple model of a closed economy where a bank competes with a bond market on both sides of its balance sheet: consumers can invest their capital in risky bonds and in safe deposits and firms can issue bonds and obtain a bank credit. Therefore, when setting the credit volume and the interest rates, the bank has to take into account the resulting equilibrium on the bond market. In particular, the bank does not face an infinitely elastic supply of funds at an exogenously given interest rate as it is commonly assumed in the literature.

Different from most models on direct versus intermediated finance in the literature our results predict a mix of financing source, i.e. neither the bank nor the bond market has its own clientele. This is confirmed by several empirical studies showing that a large fraction of firms has a mix of bank and public debt outstanding (Houston and James, 1996, Johnson, 1997), i.e. bank lending remains an important source of finance even if firms have access to public debt markets. Moreover, we have seen that the credit volume is increasing in the default risk and decreasing in the expected return of the financed projects. This provides a new explanation for the fact that banks allocate more capital to lower quality projects. Unlike earlier work, which has focused on monitoring and relationship banking, our results are driven by the risk aversion of investors and the bank's ability to diversify risk. We do not claim that the monitoring or relationship aspect of banking is not important in explaining the allocation of capital across risky projects. Instead, we want to point out that there is an additional, much simpler explanation, which does not appeal to very sophisticated bank services like monitoring or contract renegotiation and which seems to have been overlooked so far. Risk aversion is a predominant phenomenon and it should come at no surprise that it has significant influence on the allocation of capital and risk 
in an economy.

Our model also has interesting implications for the case where the proportion of the high risk and/or high expected return project gets large. In this case we have seen that there will be a screening equilibrium with adverse selection, whenever firms only differ in the default risk, and a screening equilibrium with positive selection, whenever firms only differ in the expected return of their projects. Putting this prediction to an empirical test could be very insightful since other theoretical models have not produced similar results. ${ }^{20}$

It would be desirable to distinguish empirically our explanation for the role of banks in project financing from other explanations that have been provided in the literature. However, hard evidence on the relative importance of monitoring, relationship banking and risk diversification may be difficult if not impossible to obtain, so the best we can do is to test the predictions of the theoretical models. In this respect, as we have seen, our model performs very well.

\section{A Appendix: Proofs}

Proof of Lemma 2.1: Let $\left(C, r^{C}, r^{D}\right)$ be an admissible contract with $C>0$ and let $r^{B} \geq r^{C}$ be the interest rate factor on the bond market supporting $\left(C, r^{C}, r^{D}\right)$ as a pooling or screening contract. Suppose by way of contradiction that $\hat{r}^{B}<r^{C}$ clears the bond market as well. If $\left(C, r^{C}, r^{D}\right)$ is an admissible pooling contract it follows that given $\hat{r}^{B}$ both types of firms will reject the bank's offer and demand one unit of capital on the bond market. Hence, for the bond market to clear each investor has to invest all his capital on the bond market which he will never do given his preferences as we have seen before.

It remains to consider the case where $\left(C, r^{C}, r^{D}\right)$ is an admissible screening contract. W.l.o.g. let it be the type $\theta^{1}$ firm that participates at this contract. If $\hat{r}^{B}<r^{C}$ then either both types of firms will participate and reject the bank's offer leading to the same contradiction as above. Or else only the type $\theta^{1}$ firm participates. But then the bond market cannot clear at the interest rate factor $\hat{r}^{B}$ since it cleared at $r^{B} \geq r^{C}$ : the type $\theta^{1}$ firm demands more capital on the bond market at $\hat{r}^{B}$ while the investors will invest less capital than at $r^{B}$.

\footnotetext{
${ }^{20}$ Such a test would require detailed data about bank lending, which may not be easily available. 


\section{Proof of Lemma 2.2:}

(i) Let $\left(C, r^{C}, r^{D}\right)$ be an admissible pooling contract and let $\beta$ be the corresponding belief of the investors and $r^{B}$ the interest rate factor on bonds supporting $\left(C, r^{C}, r^{D}\right)$. Then $\beta=\lambda$ and $C>0$ immediately follows from the market clearing condition and the fact that $D\left(\beta, r^{B}, r^{D}\right)>0$. This implies $r^{B} \geq r^{C}$ from the optimization problem of the firms. If, in addition, $\Gamma^{P}\left(C, r^{C}, r^{D}\right)=C\left(\bar{p}(\lambda) r^{C}-r^{D}\right) \geq 0$, then it follows that $\bar{p}(\lambda) r^{C} \geq r^{D}$ since $C>0$.

(ii) Let $\left(C, r^{C}, r^{D}\right)$ be an admissible screening contract and let $\beta$ be the corresponding belief of the investors and $r^{B}$ the interest rate factor on bonds supporting $\left(C, r^{C}, r^{D}\right)$. W.l.o.g. let $\beta=1$. From the market clearing condition on the bond market (condition (iv) of Definition 2.2) it follows that

$$
D\left(\beta, r^{B}, r^{D}\right)=1-\lambda(1-C) .
$$

Hence, $\Gamma^{S}\left(C, r^{C}, r^{D}\right)=\lambda C\left(p_{1} r^{C}-r^{D}\right)+(1-\lambda)\left(1-r^{D}\right) \geq 0$ immediately implies that $p_{1} r^{C} \geq r^{D}$ if $C>0$ since $r^{D} \geq 1$. $r^{B} \geq r^{C}$ follows as above. Since $\bar{p}(\beta)=p_{1}$ this proves our lemma.

Proof of Lemma 2.3: Let $r^{B}$ and $\hat{r}^{B}$ be two interest factors on bonds supporting the admissible contract $\left(C, r^{C}, r^{D}\right)$ and let $\beta$ be the corresponding belief of the investors. Observe that independently of $r^{B}$ it is always the same firm that is driven out of the market. Let $\Gamma^{P}\left(C, r^{C}, r^{D}\right) \geq 0$, respectively $\Gamma^{S}\left(C, r^{C}, r^{D}\right) \geq 0$. Consider first the case where $C>0$. Then, by Lemma 2.2 it follows that $r^{B} \geq r^{C}, \hat{r}^{B} \geq r^{C}, \bar{p}(\beta) r^{B} \geq r^{D}$ and $\bar{p}(\beta) \hat{r}^{B} \geq r^{D}$. Since $D\left(\beta, r^{B}, r^{D}\right)=D\left(\beta, \hat{r}^{B}, r^{D}\right)$ by the market clearing condition (iv) in Definitions 2.1 and 2.2 , it then follows that

$$
D\left(\beta, r^{B}, r^{D}\right)=(1-\bar{p}(\beta)) \frac{r^{B}}{r^{B}-r^{D}}=(1-\bar{p}(\beta)) \frac{\hat{r}^{B}}{\hat{r}^{B}-r^{D}}=D\left(\beta, \hat{r}^{B}, r^{D}\right) .
$$

Since $r^{D} \geq 1$ this implies $r^{B}=\hat{r}^{B}$.

It remains to consider the case where $C=0$. By Lemma 2.2 this can only be the case if $\left(C, r^{C}, r^{D}\right)$ is a screening contract. By the market clearing condition 
(iv) in Definition 2.2 it follows that $D\left(\beta, r^{B}, r^{D}\right)=D\left(\beta, \hat{r}^{B}, r^{D}\right)=1-\beta \lambda-(1-$ $\beta)(1-\lambda)<1$. Hence, as above we conclude that $r^{B}=\hat{r}^{B}$.

Proof of Lemma 3.1: Let $\left(C, r^{C}, r^{D}\right)$ be an admissible pooling (screening) contract and let $\beta$ be the corresponding belief of the investors and $r^{B}$ the interest rate factor on the bond market supporting $\left(C, r^{C}, r^{D}\right)$ as a pooling (screening) contract. By Lemma 2.2 we know that $C>0, r^{B} \geq r^{C}$ and $\bar{p}(\beta) r^{C} \geq r^{D}$ since $\Gamma^{P}\left(C, r^{C}, r^{D}\right) \geq 0$, respectively $\Gamma^{S}\left(C, r^{C}, r^{D}\right)>0$. (Observe that $\Gamma^{S}\left(C, r^{C}, r^{D}\right)>$ 0 implies that $C>0$.) Hence $D\left(\beta, r^{B}, r^{D}\right)=(1-\bar{p}(\beta)) \frac{r^{B}}{r^{B}-r^{D}}$ follows from the optimization problem of the investors. Now suppose $r^{B}>r^{C}$. Then $C<1$ since $C=1$ would imply $D\left(\beta, r^{B}, r^{D}\right)=1$ and hence $r^{D}=\bar{p}(\beta) r^{B}>\bar{p}(\beta) r^{C} \geq r^{D}$ which is impossible. We define

$$
\hat{r}^{C}=C r^{C}+(1-C) r^{B} .
$$

Then, obviously, $r^{B}>\hat{r}^{C}>r^{C}$. Let $\hat{r}^{B}=\hat{r}^{C}$. We will now consider separately the cases of a pooling and a screening contract.

Pooling: If $\left(C, r^{C}, r^{D}\right)$ is an admissible pooling contract, it follows that $\beta=\lambda$ by condition (iii) of a pooling contract. Then, by definition, $\bar{p}(\lambda) \hat{r}^{B}>\bar{p}(\lambda) r^{C} \geq$ $r^{D}$ which implies

$$
D\left(\lambda, \hat{r}^{B}, r^{D}\right)=(1-\bar{p}(\lambda)) \frac{\hat{r}^{B}}{\hat{r}^{B}-r^{D}}>(1-\bar{p}(\lambda)) \frac{r^{B}}{r^{B}-r^{D}}=C
$$

since $(1-\bar{p}(\lambda)) \frac{r^{B}}{r^{B}-r^{D}}$ is decreasing in $r^{B}$. Let $\hat{C}=D\left(\lambda, \hat{r}^{B}, r^{D}\right)$ and $\hat{r}^{D}=r^{D}$. Then, $\hat{C}>C$ and we will show that $\left(\hat{C}, \hat{r}^{C}, \hat{r}^{D}\right)$ is an admissible pooling contract supported by $\hat{r}^{B}$ and that $\Gamma^{P}\left(\hat{C}, \hat{r}^{C}, \hat{r}^{D}\right)>\Gamma^{P}\left(C, r^{C}, r^{D}\right)$. To this end let $\beta=\lambda$ be the correct belief of the investors. Since $\hat{r}^{B}=\hat{r}^{C}$ we get $C^{\theta^{i}}\left(\hat{C}, \hat{r}^{C}, \hat{r}^{B}\right)=\hat{C}$ for $i=1,2$, so that condition (i) of an admissible pooling contract is satisfied. Moreover, for $i=1,2$,

$$
\begin{aligned}
\mu_{i}-p_{i}\left(\hat{C} \hat{r}^{C}+(1-\hat{C}) \hat{r}^{B}\right) & =\mu_{i}-p_{i} \hat{r}^{C} \\
& =\mu_{i}-p_{i}\left(C r^{C}+(1-C) r^{B}\right) \geq K
\end{aligned}
$$


by definition of $\hat{r}^{C}$ so that the participation constrained (ii) is satisfied. Conditions (iii) and (iv) are fulfilled by definition. Finally,

$$
\Gamma^{P}\left(\hat{C}, \hat{r}^{C}, \hat{r}^{D}\right)=\hat{C}\left(\bar{p}(\lambda) \hat{r}^{C}-\hat{r}^{D}\right)>C\left(\bar{p}(\lambda) r^{C}-r^{D}\right)=\Gamma^{P}\left(C, r^{C}, r^{D}\right) .
$$

Screening: We only consider the case where $\beta=1$ is the belief of the investors corresponding to the admissible screening contract $\left(C, r^{C}, r^{D}\right)$. This implies $\bar{p}(\beta)=p_{1}$. From $p_{1} \hat{r}^{B}>p_{1} r^{C} \geq r^{D}$ it follows that $D\left(1, \hat{r}^{B}, r^{D}\right)=$ $\left(1-p_{1}\right) \frac{\hat{r}^{B}}{\hat{r}^{B}-r^{D}}>\left(1-p_{1}\right) \frac{r^{B}}{r^{B}-r^{D}}=D\left(1, r^{B}, r^{D}\right)$ by the same monotonicity argument as above. Also, from condition (iv) of an admissible screening contract it follows that $D\left(1, r^{B}, r^{D}\right)=1-\lambda(1-C)>1-\lambda$ so that $D\left(1, \hat{r}^{B}, r^{D}\right)>1-\lambda$. We define

$$
\hat{C}=\frac{D\left(1, \hat{r}^{B}, r^{D}\right)-(1-\lambda)}{\lambda}
$$

and will argue that $\left(\hat{C}, \hat{r}^{C}, \hat{r}^{D}\right)$ with $\hat{r}^{D}=r^{D}$ is an admissible screening contract that strictly increases the bank's profit over the contract $\left(C, r^{C}, r^{D}\right)$. To this end let $\beta=1$ be the correct belief of the investors. Since $\hat{r}^{B}=\hat{r}^{C}$ we get $C^{\theta^{1}}\left(\hat{C}, \hat{r}^{C}, \hat{r}^{B}\right)=\hat{C}$, so that condition (i) of an admissible screening contract is satisfied. Moreover,

$$
\begin{aligned}
\mu_{1}-p_{1}\left(\hat{C} \hat{r}^{C}+(1-\hat{C}) \hat{r}^{B}\right) & =\mu_{1}-p_{1} \hat{r}^{C} \\
& =\mu_{1}-p_{1}\left(C r^{C}+(1-C) r^{B}\right) \\
& \geq K \\
& >\mu_{2}-p_{2}\left(C r^{C}+(1-C) r^{B}\right) \\
& =\mu_{2}-p_{2} \hat{r}^{C} \\
& =\mu_{2}-p_{2}\left(\hat{C} \hat{r}^{C}+(1-\hat{C}) \hat{r}^{B}\right)
\end{aligned}
$$

by definition of $\hat{r}^{C}$ so that condition (ii) is satisfied. Conditions (iii) and (iv) are fulfilled by definition. Finally,

$$
\begin{aligned}
\Gamma^{S}\left(C, r^{C}, r^{D}\right) & =\lambda p_{1} C r^{C}+1-\lambda-D\left(1, r^{B}, r^{D}\right) r^{D} \\
& =\left(D\left(1, r^{B}, r^{D}\right)-(1-\lambda)\right) p_{1} r^{C}+1-\lambda-D\left(1, r^{B}, r^{D}\right) r^{D} \\
& =D\left(1, r^{B}, r^{D}\right)\left(p_{1} r^{C}-r^{D}\right)+(1-\lambda)\left(1-p_{1} r^{C}\right)
\end{aligned}
$$




$$
\begin{aligned}
& <D\left(1, \hat{r}^{B}, \hat{r}^{D}\right)\left(p_{1} r^{C}-\hat{r}^{D}\right)+(1-\lambda)\left(1-p_{1} r^{C}\right) \\
& <D\left(1, \hat{r}^{B}, \hat{r}^{D}\right)\left(p_{1} \hat{r}^{C}-\hat{r}^{D}\right)+(1-\lambda)\left(1-p_{1} \hat{r}^{C}\right) \\
& =\Gamma^{S}\left(\hat{C}, \hat{r}^{C}, \hat{r}^{D}\right),
\end{aligned}
$$

where the second equality follows from the market clearing condition on the bond market and the last inequality follows from the fact that $\hat{r}^{C}>r^{C}$ and $D\left(1, \hat{r}^{B}, \hat{r}^{D}\right)>1-\lambda$.

Proof of Theorem 3.1: The necessity and sufficiency of the condition $\bar{p}(\lambda) \min _{i=1,2}\left\{\sigma_{i}\left(\mu_{i}-K\right)\right\} \geq 1$ immediately follows from the constraints of the optimization problem (P). Now let this condition be satisfied. Then we compute

$$
\frac{\partial}{\partial r^{C}} F^{P}\left(r^{C}, r^{D}\right)=\frac{1-\bar{p}(\lambda)}{\left(r^{C}-r^{D}\right)^{2}}\left(\bar{p}(\lambda)\left(r^{C}\right)^{2}-2 \bar{p}(\lambda) r^{C} r^{D}+\left(r^{D}\right)^{2}\right)
$$

which is easily seen to be positive for all $r^{C} \geq 0, r^{D} \geq 1$, since $\bar{p}(\lambda)<1$. Also

$$
\frac{\partial}{\partial r^{D}} F^{P}\left(r^{C}, r^{D}\right)=-(1-\bar{p}(\lambda))^{2} \frac{\left(r^{C}\right)^{2}}{\left(r^{C}-r^{D}\right)^{2}}
$$

which is negative for all $r^{C} \geq 0, r^{D} \geq 1$ since $\bar{p}(\lambda)<1$. Hence, the solution to (P) is given by $\hat{r}^{C}=\min _{i=1,2}\left\{\sigma_{i}\left(\mu_{i}-K\right)\right\}, \hat{r}^{D}=1$. Since $F^{P}\left(\hat{r}^{C}, \hat{r}^{D}\right)$ is the maximum profit the bank can achieve with a pooling contract, the optimal pooling contract is given by $\left(\hat{C}, \hat{r}^{C}, \hat{r}^{D}\right)$ with $\hat{C}=(1-\bar{p}(\lambda)) \frac{\hat{r}^{C}}{\hat{r}^{C}-1}$. Obviously, $\hat{C}<1$ if and only if $\bar{p}(\lambda) \hat{r}^{C}>1$.

Proof of Theorem 3.2: Let $p_{1} r^{C} \geq r^{D} \geq 1$. Then

$$
\frac{\partial}{\partial r^{D}} F^{S}\left(r^{C}, r^{D}\right)=-\left(1-p_{1}\right)^{2} \frac{\left(r^{C}\right)^{2}}{\left(r^{C}-r^{D}\right)^{2}}<0
$$

which implies that $F^{S}\left(r^{C}, r^{D}\right)$ is maximized for $\tilde{r}^{D}=1$. Hence, it remains to solve the following optimization problem

$$
\begin{aligned}
& \operatorname{Max}_{r^{C}} F^{S}\left(r^{C}, 1\right)=\left(p_{1} r^{C}-1\right)\left(\left(1-p_{1}\right) \frac{r^{C}}{r^{C}-1}-(1-\lambda)\right) \\
& \text { s.t. } p_{1} r^{C} \geq 1 \text { and } \\
& \sigma_{1}\left(\mu_{1}-K\right) \geq r^{C}>\sigma_{2}\left(\mu_{2}-K\right) .
\end{aligned}
$$


We compute

$$
\frac{\partial}{\partial r^{C}} F^{S}\left(r^{C}, 1\right)=\frac{1-p_{1}}{\left(r^{C}-1\right)^{2}}\left(p_{1}\left(r^{C}\right)^{2}-2 p_{1} r^{C}+1\right)-(1-\lambda) p_{1}
$$

and $\frac{\partial^{2}}{\partial\left(r^{C}\right)^{2}} F^{S}\left(r^{C}, 1\right)<0$ since $r^{C}>1$. Hence, $F^{S}\left(r^{C}, 1\right)$ is strictly concave in ${ }^{C}$ for $r^{C}$ with $p_{1} r^{C} \geq 1$. From (3) it follows that $\frac{\partial}{\partial r^{C}} F^{S}\left(r^{C}, 1\right)>0$ for all $r^{C}$ if $\lambda \geq p_{1}$. In this case the solution to (2) is given by $\tilde{r}^{C}=\sigma_{1}\left(\mu_{1}-K\right)$.

If $\lambda<p_{1}$, then for $r^{C}$ with $p_{1} r^{C} \geq 1, \frac{\partial}{\partial r^{C}} F^{S}\left(r^{C}, 1\right)>0$ if and only if $r^{C}<$ $1+\left(1-p_{1}\right) / \sqrt{p_{1}\left(p_{1}-\lambda\right)}$. Hence, the solution to $(2)$ is given by

$$
\tilde{r}^{C}=\min \left\{1+\frac{1-p_{1}}{\sqrt{p_{1}\left(p_{1}-\lambda\right)}}, \sigma_{1}\left(\mu_{1}-K\right)\right\}
$$

whenever $\tilde{r}^{C}>\sigma_{2}\left(\mu_{2}-K\right)$. In this case let

$$
\tilde{C}=\frac{1}{\lambda}\left(\left(1-p_{1}\right) \frac{\tilde{r}^{C}}{\tilde{r}^{C}-1}-(1-\lambda)\right) .
$$

Since $p_{1} \tilde{r}^{C}>1$ it follows that

$$
\frac{\partial}{\partial \lambda} F^{S}\left(\tilde{r}^{C}, 1\right)=p_{1} \tilde{r}^{C}-1>0
$$

Moreover, $\lim _{\lambda \rightarrow 0} F^{S}\left(\tilde{r}^{C}, 1\right)=0$. Together this implies $F^{S}\left(\tilde{r}^{C}, 1\right)>0$ for all $\lambda>0$. Hence, $\left(\tilde{C}, \tilde{r}^{C}, \tilde{r}^{D}\right)$ is the profit maximizing screening contract and it yields strictly positive profits for the bank.

If $\tilde{r}^{C} \leq \sigma_{2}\left(\mu_{2}-K\right)$ there exists no solution to (2) and hence no profit maximizing screening contract.

Proof of Lemma 3.2: Let $\left(C, r^{C}, r^{D}\right)$ be an admissible pooling contract with $\bar{p}(\lambda) r^{C} \geq r^{D}$. Let $r^{B}$ be the interest rate factor supporting $\left(C, r^{C}, r^{D}\right)$ as a pooling contract and let $\tilde{r}^{B}$ be the interest rate factor supporting $\left(C, r^{C}, r^{D}\right)$ as a screening contract. Then $\tilde{r}^{B}>r^{B}$ and

$$
C=(1-\bar{p}(\lambda)) \frac{r^{B}}{r^{B}-r^{D}}=\frac{1}{\lambda}\left(\left(1-p_{1}\right) \frac{\tilde{r}^{B}}{\tilde{r}^{B}-r^{D}}-(1-\lambda)\right)
$$


by the market clearing conditions in the definition of an admissible pooling and screening contract. This implies

$$
\begin{gathered}
\lambda C<\frac{1-p_{1}}{1-\bar{p}(\lambda)} C-(1-\lambda) \\
\Longleftrightarrow 1-\lambda<C \frac{1-p_{1}-\lambda(1-\bar{p}(\lambda))}{1-\bar{p}(\lambda)} .
\end{gathered}
$$

Now let $\left(\hat{C}, \hat{r}^{C}, \hat{r}^{D}\right)$ be a profit maximizing pooling contract with $\Gamma^{P}\left(\hat{C}, \hat{r}^{C}, \hat{r}^{D}\right) \geq 0$. In order to show that $\left(\hat{C}, \hat{r}^{C}, \hat{r}^{D}\right)$ is not an admissible screening contract it suffices to show that $\hat{C}$ violates (4). Let $\alpha_{2}=\mu_{2}-K$. Since $\bar{p}(\lambda) \hat{r}^{C} \geq \hat{r}^{D}$ (nonnegative profits of the bank) we can apply the argument above. Consider first the case where $\sigma_{1}=\sigma_{2}$. Then $p_{1}=p_{2}=\bar{p}(\lambda)$ for all $\lambda$ and (4) transforms to

$$
1-\lambda<\hat{C} \frac{\left(1-p_{1}\right)(1-\lambda)}{1-p_{1}}
$$

which is impossible since $\hat{C} \leq 1$.

Now consider the case where $\sigma_{1} \neq \sigma_{2}$ and $\sigma_{1} \leq 2 \sigma_{2} \frac{\alpha_{2}}{\alpha_{2}+1}$. By Theorem 3.1 we know that $\hat{C}=(1-\bar{p}(\lambda)) \frac{\alpha_{2}}{\alpha_{2}-p_{2}}$. Using this expression (4) is equivalent to

$$
\alpha_{2}\left(p_{1}-p_{2}\right)\left(\lambda^{2}-\lambda \frac{p_{2}\left(1-\alpha_{2}\right)}{\alpha_{2}\left(p_{1}-p_{2}\right)}+\frac{p_{2}-\alpha_{2} p_{1}}{\alpha_{2}\left(p_{1}-p_{2}\right)}\right)>0 .
$$

If $p_{1}>p_{2}$, then (5) is violated for all $\lambda$ with

$$
\frac{p_{2}-\alpha_{2} p_{1}}{\alpha_{2}\left(p_{1}-p_{2}\right)} \leq \lambda \leq 1
$$

Since $\bar{p}(\lambda) \hat{r}^{C} \geq \hat{r}^{D}=1$ one immediately verifies that (5) is indeed violated for the given $\lambda$, i.e. $\left(\hat{C}, \hat{r}^{C}, \hat{r}^{D}\right)$ is not an admissible screening contract.

If $p_{1}<p_{2}$, then (5) is violated for all $\lambda \leq 1$. Hence, as in the previous case we have proved that $\left(\hat{C}, \hat{r}^{C}, \hat{r}^{D}\right)$ is not an admissible screening contract.

Proof of Lemma 3.3: Define $\alpha_{1}=\mu_{1}-K$ and $\alpha_{2}=\mu_{2}-K$. Under the assumptions in the statement of the Lemma let $\left(\hat{C}, \hat{r}^{C}, \hat{r}^{D}\right)$ be a profit maximizing pooling contract for some $\hat{\lambda}>0$ such that $\Gamma^{P}\left(\hat{C}, \hat{r}^{C}, \hat{r}^{D}\right) \geq 0$. Let $r^{B}$ be 
the interest rate factor on the bond market supporting $\left(\hat{C}, \hat{r}^{C}, \hat{r}^{D}\right)$ as a pooling contract. From Theorem 3.1 we know that $r^{B}=\hat{r}^{C}=\alpha_{2} / p_{2}, \hat{r}^{D}=1$, and $\hat{C}=(1-\bar{p}(\hat{\lambda})) \frac{\alpha_{2}}{\alpha_{2}-p_{2}}$. Then, $\left(\hat{C}, \hat{r}^{C}, \hat{r}^{D}\right)$ is also an admissible screening contract if and only if there exists $\hat{r}^{B}>r^{B}$ such that

$$
\hat{C}=\frac{1}{\hat{\lambda}}\left(\left(1-p_{1}\right) \frac{\hat{r}^{B}}{\hat{r}^{B}-r^{D}}-(1-\hat{\lambda})\right)
$$

and $\hat{C} \hat{r}^{C}+(1-\hat{C}) \hat{r}^{B} \leq \sigma_{1} \alpha_{1}$.

From equation (6) it follows that $\hat{r}^{B}>r^{B}$ if and only if

$$
\begin{gathered}
\hat{\lambda} \hat{C}<\frac{1-p_{1}}{1-\bar{p}(\hat{\lambda})} \hat{C}-(1-\hat{\lambda}) \\
\Longleftrightarrow \quad \alpha_{2}\left(p_{1}-p_{2}\right)\left(\hat{\lambda}^{2}-\hat{\lambda} \frac{p_{2}\left(1-\alpha_{2}\right)}{\alpha_{2}\left(p_{1}-p_{2}\right)}+\frac{p_{2}-\alpha_{2} p_{1}}{\alpha_{2}\left(p_{1}-p_{2}\right)}\right)>0 .
\end{gathered}
$$

Also, from equation (6) it follows that

$$
\hat{r}^{B}=\frac{\hat{\lambda} \hat{C}+1-\hat{\lambda}}{\hat{\lambda} \hat{C}+p_{1}-\hat{\lambda}}
$$

\section{Case 1: $\mathbf{p}_{\mathbf{1}}>\mathbf{p}_{\mathbf{2}}$}

Let $\left(C, r^{C}, r^{D}\right)$ be a profit maximizing pooling contract for some $\lambda>0$ such that $\Gamma^{P}\left(C, r^{C}, r^{D}\right) \geq 0$. Since $p_{1}>p_{2}$ it follows that $\bar{p}(\lambda)$ is increasing in $\lambda$. Hence, for all $\hat{\lambda} \geq \lambda$ there exists a profit maximizing pooling contract giving the bank a nonnegative profit. One verifies that the inequality in (9) is satisfied for all $\hat{\lambda}$ under the conditions of the lemma and given that $p_{1}>p_{2}$. Moreover, from (10) and $\hat{C} \rightarrow\left(1-p_{1}\right) \alpha_{2} /\left(\alpha_{2}-p_{2}\right)$ for $\hat{\lambda} \rightarrow 1$, it follows that $\hat{r}^{B} \rightarrow \alpha_{2} / p_{2}$ for $\hat{\lambda} \rightarrow 1$. Hence, $\hat{r}^{B}<\alpha_{1} / p_{1}$ if $\hat{\lambda}$ is close to 1 since by assumption $\alpha_{2} / p_{2}<\alpha_{1} / p_{1}$. Choose $\hat{\lambda}$ such that the corresponding $\hat{r}^{B}$ as defined in (10) satisfies $\hat{r}^{B}<\alpha_{1} / p_{1}$ and let $\left(\hat{C}, \hat{r}^{C}, \hat{r}^{D}\right)$ be the profit maximizing pooling contract for $\hat{\lambda}$. Our arguments show that (6) and (7) are satisfied so that $\left(\hat{C}, \hat{r}^{C}, \hat{r}^{D}\right)$ is also an admissible screening contract.

\section{Case 2: $\mathbf{p}_{1}<\mathbf{p}_{2}$}

Let $\left(C, r^{C}, r^{D}\right)$ be a profit maximizing pooling contract for some $\lambda>0$ such that $\Gamma^{P}\left(C, r^{C}, r^{D}\right) \geq 0$. It is straightforward to see that the inequality in (9) is 
satisfied for all $\hat{\lambda}$ such that $\lambda_{1}<\hat{\lambda}<1$, where

$$
\lambda_{1}=\frac{\alpha_{2} p_{1}-p_{2}}{\alpha_{2}\left(p_{2}-p_{1}\right)} .
$$

Consider first the case where $\lambda_{1} \geq 0$. Then $\bar{p}(\hat{\lambda}) \hat{r}^{C}=\bar{p}(\hat{\lambda}) \alpha_{2} / p_{2} \geq 1$ for all $\hat{\lambda}$, where $\left(\hat{C}, \hat{r}^{C}, \hat{r}^{D}\right)$ is the corresponding profit maximizing pooling contract. Hence, as above we can choose $\hat{\lambda}$ close to 1 such that $\hat{r}^{B}<\alpha_{1} / p_{1}$ and the corresponding profit maximizing pooling contract gives nonnegative profits and is an admissible screening contract.

Consider now the case where $\lambda_{1}<0$. Then the inequality in (9) is fulfilled for all $\hat{\lambda}$. Since $\bar{p}(\lambda) r^{C}=\bar{p}(\lambda) \alpha_{2} / p_{2} \geq 1, \bar{p}(\lambda)$ is decreasing in $\lambda$ (because $p_{1}<p_{2}$ ) and $\bar{p}(1) \alpha_{2} / p_{2}<1$ (because $\lambda_{1}<0$ ), it follows that there exists $\hat{\lambda} \geq \lambda$ such that $\bar{p}(\hat{\lambda}) \alpha_{2} / p_{2}=1$. Hence, for the corresponding profit maximizing pooling contract $\left(\hat{C}, \hat{r}^{C}, \hat{r}^{D}\right)$ it is true that $\hat{C}=1$ and therefore

$$
\hat{C} \hat{r}^{C}+(1-\hat{C}) \hat{r}^{B}=\hat{r}^{C}=\alpha_{2} / p_{2}<\alpha_{1} / p_{1}
$$

Thus, again (6) and (7) are satisfied, i.e. $\left(\hat{C}, \hat{r}^{C}, \hat{r}^{D}\right)$ is an admissible screening contract.

Proof of Theorem 3.3: Let $\theta^{1}=\left(\mu_{1}, \sigma_{1}\right)$ and $\theta^{2}=\left(\mu_{2}, \sigma_{2}\right)$ be given with $\sigma_{1}\left(\mu_{1}-K\right)>\sigma_{2}\left(\mu_{2}-K\right)$. Define $\alpha_{1}=\mu_{1}-K$ and $\alpha_{2}=\mu_{2}-K$. Then

$$
\stackrel{*}{\Gamma}^{P}(\lambda)=(1-\bar{p}(\lambda)) \frac{\alpha_{2}}{\alpha_{2}-p_{2}}\left(\frac{\bar{p}(\lambda)}{p_{2}} \alpha_{2}-1\right)
$$

is the profit at the best pooling contract whenever this profit is nonnegative and

$$
\stackrel{*}{\Gamma}^{S}(\lambda)=\left(p_{1} \tilde{r}^{C}-1\right)\left(\left(1-p_{1}\right) \frac{\tilde{r}^{C}}{\tilde{r}^{C}-1}-(1-\lambda)\right)
$$

is the profit from the best screening contract whenever $\tilde{r}^{C}>\sigma_{2} \alpha_{2}$, where

$$
\tilde{r}^{C}= \begin{cases}\sigma_{1} \alpha_{1} & , \lambda \geq p_{1} \\ \min \left\{1+\frac{1-p_{1}}{\sqrt{p_{1}\left(p_{1}-\lambda\right)}}, \sigma_{1} \alpha_{1}\right\} & , \text { else }\end{cases}
$$

Moreover, from the proof of Theorem 3.2 we know that $\Gamma^{*}(\lambda)$ gives an upper bound for the profit from a screening contract also in the case where $\tilde{r}^{C} \leq \sigma_{2} \alpha_{2}$. 
Since

$$
\frac{\bar{p}(\lambda)}{p_{2}} \alpha_{2} \geq \frac{\min \left\{p_{1}, p_{2}\right\}}{p_{2}} \alpha_{2}>1
$$

for all $\lambda$ whenever $\sigma_{1}=\sigma_{2}$ or $\sigma_{1} \neq \sigma_{2}$ and $\sigma_{1} \leq 2 \sigma_{2} \frac{\alpha_{2}}{\alpha_{2}+1}$, it follows that $\stackrel{*}{\Gamma}^{P}(\lambda)>0$ is bounded away from 0 for all $\lambda>0$. Hence, from $\lim _{\lambda \rightarrow 0} \stackrel{*}{\Gamma}^{S}(\lambda)=0$ we conclude that $\stackrel{*}{\Gamma}^{S}(\lambda)<{ }^{*} P(\lambda)$ if $\lambda$ is sufficiently small. Moreover,

$$
\begin{aligned}
& \lim _{\lambda \rightarrow 1} \stackrel{*}{\Gamma}^{S}(\lambda)=\left(1-p_{1}\right) \frac{\alpha_{1}}{\alpha_{1}-p_{1}}\left(\alpha_{1}-1\right) \quad \text { and } \\
& \lim _{\lambda \rightarrow 1} \stackrel{*}{\Gamma} P(\lambda)=\left(1-p_{1}\right) \frac{\alpha_{2}}{\alpha_{2}-p_{2}}\left(\frac{p_{1}}{p_{2}} \alpha_{2}-1\right) .
\end{aligned}
$$

Hence, $\lim _{\lambda \rightarrow 1} \stackrel{*}{\Gamma}^{S}(\lambda)>\lim _{\lambda \rightarrow 1} \stackrel{*}{\Gamma}^{P}(\lambda)$ if and only if

$$
\frac{\alpha_{1}}{\alpha_{1}-p_{1}}\left(\alpha_{1}-1\right)>\frac{\alpha_{2}}{\alpha_{2}-p_{2}}\left(\frac{p_{1}}{p_{2}} \alpha_{2}-1\right) .
$$

The right hand side of this inequality is easily seen to be increasing in $\alpha_{2}$. Since by assumption $\sigma_{1} \alpha_{1}>\sigma_{2} \alpha_{2}$ it follows that $\alpha_{2}<\alpha_{1} p_{2} / p_{1}$ and therefore (12) is satisfied.

We further observe that $\Gamma^{*}(\lambda)$ is a concave function in $\lambda$ while $\Gamma^{*}(\lambda)$ is an increasing convex function in $\lambda$ since

$$
\frac{d}{d \lambda} \Gamma^{*} S(\lambda)=p_{1} \tilde{r}^{C}-1
$$

is positive $\left(\tilde{r}^{C}>\sigma_{1}\right)$ and nondecreasing in $\lambda$ because $\tilde{r}^{C}$ is nondecreasing in $\lambda$.

Consider the following cases.

(i) Let $\sigma_{1}=\sigma_{2}=\sigma$ and $p=1 / \sigma$. Then $\stackrel{*}{\Gamma}^{P}(\lambda)$ is constant while $\stackrel{*}{\Gamma}^{S}(\lambda)$ is strictly increasing in $\lambda$. Hence from our observations above it follows that there exists a unique $\lambda^{*}, 0<\lambda^{*}<1$, such that

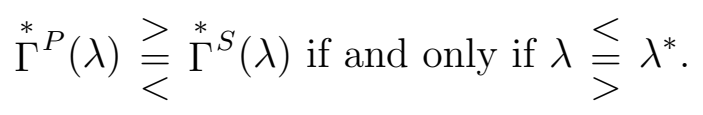

It remains to show that there exists a profit maximizing screening contract for $\lambda>\lambda^{*}$. From the definition of $\tilde{r}^{C}$ in (11) it follows that $\tilde{r}^{C} \rightarrow \sigma<\sigma \alpha_{2}$ for $\lambda \rightarrow 0$. Hence, there exists $\lambda^{0}$ such that $\tilde{r}^{C}=\sigma \alpha_{2}$ and there exists a 
profit maximizing screening contract if and only if $\lambda>\lambda^{0}$. We will show that $\lambda^{*}>\lambda^{0}$ for the intersection point $\lambda^{*}$ between $\stackrel{*}{\Gamma}^{P}(\lambda)$ and $\stackrel{*}{\Gamma}^{S}(\lambda)$.

$$
\begin{aligned}
& \stackrel{*}{\Gamma}^{S}\left(\lambda^{0}\right)=\left(\alpha_{2}-1\right)\left((1-p) \frac{\alpha_{2}}{\alpha_{2}-p}-\left(1-\lambda^{0}\right)\right), \\
& \stackrel{*}{\Gamma}^{P}\left(\lambda^{0}\right)=(1-p) \frac{\alpha_{2}}{\alpha_{2}-p}\left(\alpha_{2}-1 .\right)
\end{aligned}
$$

Hence, $\stackrel{*}{\Gamma} P\left(\lambda^{0}\right)>\stackrel{*}{\Gamma}^{S}\left(\lambda^{0}\right)$, i.e. $\lambda^{*}>\lambda^{0}$.

(ii) Let $\sigma_{1} \neq \sigma_{2}$ and $\sigma_{1} \leq 2 \sigma_{2} \frac{\alpha_{2}}{\alpha_{2}+1}$. As we have noted above, $\stackrel{*}{\Gamma}^{S}(\lambda)$ is convex in $\lambda$. Since $\sigma_{1} \neq \sigma_{2}$ it follows that $\Gamma^{*} P(\lambda)$ is strictly concave in $\lambda$. Hence, from $\lim _{\lambda \rightarrow 1} \stackrel{*}{\Gamma}^{S}(\lambda)>\lim _{\lambda \rightarrow 1} \stackrel{*}{\Gamma}^{P}(\lambda)$ and $\lim _{\lambda \rightarrow 0} \stackrel{*}{\Gamma}^{S}(\lambda)<\lim _{\lambda \rightarrow 0} \stackrel{*}{\Gamma}^{P}(\lambda)$ it follows that there exists a unique $\lambda^{*}, 0<\lambda^{*}<1$, such that

$$
\stackrel{*}{\Gamma}^{P}(\lambda) \underset{\overline{<}}{\gtrless} \Gamma^{S}(\lambda) \text { if and only if } \lambda \underset{\equiv}{\risingdotseq} \lambda^{*}
$$

Thus, the bank's profits are maximized at a pooling contract for $\lambda \leq \lambda^{*}$ and at a screening contract for $\lambda \geq \lambda^{*}$. It remains to show that there exists a profit maximizing screening contract for $\lambda \geq \lambda^{*}$ whenever $\alpha_{1}$ is sufficiently small.

There exists a profit maximizing screening contract for $\lambda \geq p_{1}$ since in this case $\tilde{r}^{C}=\sigma_{1} \alpha_{1}>\sigma_{2} \alpha_{2}$ for $\tilde{r}^{C}$ as defined in (11). Hence, to prove our claim it is sufficient to show that $\stackrel{*}{\Gamma}^{P}\left(p_{1}\right)>\stackrel{*}{\Gamma}^{S}\left(p_{1}\right)$. Provided that $\alpha_{1}$ is sufficiently small this immediately follows from

$$
\begin{aligned}
& \stackrel{*}{\Gamma}^{S}\left(p_{1}\right)=p_{1}\left(1-p_{1}\right) \frac{\alpha_{1}-1}{\alpha_{1}-p_{1}}, \\
& \stackrel{*}{\Gamma}^{P}\left(p_{1}\right)=\left(1-\bar{p}\left(p_{1}\right)\right) \frac{\alpha_{2}}{\alpha_{2}-p_{2}}\left(\frac{\bar{p}\left(p_{1}\right)}{p_{2}} \alpha_{2}-1\right)
\end{aligned}
$$

since $\left(\alpha_{1}-1\right) /\left(\alpha_{1}-p_{1}\right)$ is increasing in $\alpha_{1}$. This concludes the proof. 


\section{References}

Besanko, D., and G. Kanatas (1993): "Credit Market Equilibrium with Bank Monitoring and Moral Hazard," The Review of Financial Studies, 6, 213-232.

Bester, H. (1985): "Screening vs. Rationing in Credit Markets with Imperfect Information," The American Economic Review, 75, 850-855.

Bisin, A., And P. GotTardi (1999): "Competitive Equilibria with Asymmetric Information," Journal of Economic Theory, 87, 1-48.

Bolton, P., and X. Freixas (2000): "Equity, Bonds, and Band Debt: Capital Structure and Financial Market Equilibrium under Asymmetric Information," Journal of Political Economy, 108, 324-351.

Chemmanur, T. J., and P. Fulghieri (1994): "Reputation, Renegotiation, and the Choice between Bank Loans and Publicly Traded Debt," The Review of Financial Studies, 7, 475-506.

Cosimano, T. F., And B. McDonald (1998): "What's Different among Banks?," Journal of Monetary Economics, 41, 57-70.

Diamond, D. W. (1991): "Monitoring and Reputation: The Choice between Bank Loans and Directly Placed Debt," Journal of Political Economy, 99, 689-721.

FAmA, E. F. (1985): "What's Different about Banks?," Journal of Monetary Economics, 15, 29-39.

Feldman, M., And C. Gilles (1985): "An Expository Note on Individual Risk without Aggregate Uncertainty," Journal of Economic Theory, 35, 26-32.

Gale, D., and M. Hellwig (1985): "Incentive-Compatible Debt Contracts: The One-Period Problem," Review of Economic Studies, 52, 647-663.

Hellmann, T., and J. Stiglitz (2000): "Credit and Equity Rationing in Markets with Adverse Selection," European Economic Review, 44, 281-304. 
Holmstrom, B., and J. Tirole (1997): "Financial Intermediation, Loanable Funds, and the Real Sector," Quarterly Journal of Economics, 112, 663-691.

Hoshi, T., A. Kashyap, and D. Scharfstein (1993): "The Choice between Public and Private Debt: An Analysis of Post-Deregulation Corporate Financing in Japan," Working Paper No. 4421, NBER.

Houston, J., and C. James (1996): "Bank Information Monopolies and the Mix of Private and Public Debt," The Journal of Finance, 51, 1863-1889.

JAmEs, C. (1987): "Some Evidence on the Uniqueness of Bank Loans," Journal of Financial Economics, 19, 217-235.

Johnson, S. A. (1997): "An Empirical Analysis of the Determinants of Corporate Debt Ownership Structure," Journal of Financial and Quantitative Analysis, 32, 47-69.

JudD, K. L. (1985): "The Law of Large Numbers with a Continuum of IID Random Variables," Journal of Economic Theory, 35, 19-25.

Krishnaswami, S., P. A. Spindt, and V. Subramaniam (1999): "Information Asymmetry, Monitoring, and the Placement Structure of Corporate Debt," Journal of Financial Economics, 51, 407-434.

RaJan, R. G. (1992): "Insiders and Outsiders: The Choice between Informed and Arm's Length Debt," The Journal of Finance, 47, 1367-1400.

Stiglitz, J. E., And A. Weiss (1981): "Credit Rationing in Markets with Imperfect Information," American Economic Review, 71, 393-410. 